\title{
Time-Filtered Navier-Stokes Approach and Emulation of Turbulence-Chemistry Interaction
}

Nan-Suey Liu and Thomas Wey

Glenn Research Center, Cleveland, Ohio

Tsan-Hsing Shih

Ohio Aerospace Institute, Brook Park, Ohio 


\section{NASA STI Program . . . in Profile}

Since its founding, NASA has been dedicated to the advancement of aeronautics and space science. The NASA Scientific and Technical Information (STI) program plays a key part in helping NASA maintain this important role.

The NASA STI Program operates under the auspices of the Agency Chief Information Officer. It collects, organizes, provides for archiving, and disseminates NASA's STI. The NASA STI program provides access to the NASA Aeronautics and Space Database and its public interface, the NASA Technical Reports Server, thus providing one of the largest collections of aeronautical and space science STI in the world. Results are published in both non-NASA channels and by NASA in the NASA STI Report Series, which includes the following report types:

- TECHNICAL PUBLICATION. Reports of completed research or a major significant phase of research that present the results of NASA programs and include extensive data or theoretical analysis. Includes compilations of significant scientific and technical data and information deemed to be of continuing reference value. NASA counterpart of peer-reviewed formal professional papers but has less stringent limitations on manuscript length and extent of graphic presentations.

- TECHNICAL MEMORANDUM. Scientific and technical findings that are preliminary or of specialized interest, e.g., quick release reports, working papers, and bibliographies that contain minimal annotation. Does not contain extensive analysis.

- CONTRACTOR REPORT. Scientific and technical findings by NASA-sponsored contractors and grantees.
- CONFERENCE PUBLICATION. Collected papers from scientific and technical conferences, symposia, seminars, or other meetings sponsored or cosponsored by NASA.

- SPECIAL PUBLICATION. Scientific, technical, or historical information from NASA programs, projects, and missions, often concerned with subjects having substantial public interest.

- TECHNICAL TRANSLATION. Englishlanguage translations of foreign scientific and technical material pertinent to NASA's mission.

Specialized services also include creating custom thesauri, building customized databases, organizing and publishing research results.

For more information about the NASA STI program, see the following:

- Access the NASA STI program home page at http://www.sti.nasa.gov

- E-mail your question to help@sti.nasa.gov

- Fax your question to the NASA STI Information Desk at 443-757-5803

- Phone the NASA STI Information Desk at 443-757-5802

- Write to: STI Information Desk NASA Center for AeroSpace Information 7115 Standard Drive Hanover, MD 21076-1320 


\section{Time-Filtered Navier-Stokes Approach and Emulation of Turbulence-Chemistry Interaction}

Nan-Suey Liu and Thomas Wey

Glenn Research Center, Cleveland, Ohio

Tsan-Hsing Shih

Ohio Aerospace Institute, Brook Park, Ohio

Prepared for the

51st Aerospace Sciences Meeting

sponsored by the American Institute of Aeronautics and Astronautics

Grapevine, Texas, January 7-10, 2013

National Aeronautics and

Space Administration

Glenn Research Center

Cleveland, Ohio 44135 


\section{Acknowledgments}

This work has been supported by the NASA Fundamental Aeronautics Program.

This report is a formal draft or working paper, intended to solicit comments and ideas from a technical peer group.

This report contains preliminary findings, subject to revision as analysis proceeds.

Trade names and trademarks are used in this report for identification only. Their usage does not constitute an official endorsement, either expressed or implied, by the National Aeronautics and Space Administration.

This work was sponsored by the Fundamental Aeronautics Program at the NASA Glenn Research Center.

Level of Review: This material has been technically reviewed by technical management.

Available from

NASA Center for Aerospace Information 7115 Standard Drive

Hanover, MD 21076-1320
National Technical Information Service 5301 Shawnee Road Alexandria, VA 22312

Available electronically at http://www.sti.nasa.gov 


\title{
Time-Filtered Navier-Stokes Approach and Emulation of Turbulence-Chemistry Interaction
}

\author{
Nan-Suey Liu and Thomas Wey \\ National Aeronautics and Space Administration \\ Glenn Research Center \\ Cleveland, Ohio 44135 \\ Tsan-Hsing Shih \\ Ohio Aerospace Institute \\ Brook Park, Ohio 44142
}

\begin{abstract}
This paper describes the time-filtered Navier-Stokes approach capable of capturing unsteady flow structures important for turbulent mixing and an accompanying subgrid model directly accounting for the major processes in turbulence-chemistry interaction. They have been applied to the computation of twophase turbulent combustion occurring in a single-element lean-direct-injection combustor. Some of the preliminary results from this computational effort are presented in this paper.
\end{abstract}

\section{Nomenclature}

$\begin{array}{ll}\text { CFD } & \text { computational fluid dynamics } \\ \text { DNS } & \text { direct numerical simulation } \\ \text { LES } & \text { large-eddy simulation } \\ \text { RANS } & \text { Reynolds-averaged Navier-Stokes approach } \\ \text { URANS } & \text { unsteady RANS } \\ \text { TFNS } & \text { time-filtered Navier-Stokes approach } \\ \text { SGS } & \text { subgrid scale } \\ \text { SFC } & \text { subfilter component } \\ \text { FCP } & \text { filtering-control parameter } \\ \text { LEM } & \text { linear-eddy mixing model } \\ \text { LDI } & \text { lean-direct injection } \\ \text { VBB } & \text { vortex-breakdown bubble } \\ \text { PVC } & \text { precessing-vortex core }\end{array}$

\subsection{Introduction}

High-fidelity simulation of liquid combustion in practical engineering devices remains an elusive target in spite of significant advances in physical models and numerical methods over the past decade. Within these devices, there are a broad range of intricate physical and chemical phenomena, with liquid fuel atomization and spray, as well as turbulence-chemistry interaction, being two of the most important processes. The most accurate and straightforward numerical approach to fluid flow problems is to solve the Navier-Stokes equations without filtering and approximation other than numerical discretizations whose errors are to be controlled by highly accurate numerical schemes. This approach is known as the direct numerical simulation (DNS). Although the governing equations are solved directly in DNS, the use of models to accommodate the multiphase formulation and interaction is still unavoidable. Much more research in this area is needed. Modeling and simulations of fuel injection and spray combustion is a very difficult task, in fact, many existing large-eddy simulation (LES) of spray flow and combustion invoke the same liquid-phase models as those used in the traditional Reynolds-averaged Navier-Stokes (RANS) 
approach, with a subgrid-scale (SGS) model used for the gas-phase turbulence. LES uses spatial filtering to explicitly account for flow structures larger than the filter width, the filtering in LES leads to unknown terms in the filtered equations, and these so-called SGS terms need to be modeled to form a closed set of the fluid flow governing equations. For chemically reacting flow, modeling of the filtered term arising from the production and destruction of chemical species is quite challenging, whether the approach is the traditional RANS or LES, as the turbulence-chemistry interaction is present throughout the turbulent spectrum. In any event, for liquid fueled combustion processes, unsteadiness is a dominant feature of the fluid dynamics, furthermore, the flame structure is very complex and locally (both in space and time) can range from nonpremixed to premixed burning. Thus, the prerequisites for improved simulation of multiphase turbulent combustion include the ability of the turbulence model to capture the unsteady turbulent structures responsible for the fuel-oxidizer mixing, and that the modeled process of turbulencechemistry interaction can account for the multiregime-flame structure in these combustors. This paper describes some of the recent progress made in these two areas in the framework of the time-filtered Navier-Stokes (TFNS) approach.

Before we focus on the TFNS approach, a few words on the fundamental characteristics of the conventional LES is in order. In the framework of conventional LES, the filtered equations are established by applying a spatial filter to the exact form of the governing equations. The filter width is typically the local grid size; in addition, the eddy viscosity uses the local grid size as a model parameter. Therefore, the grid resolution and the model fidelity are formally linked, and, in principle, a grid independent solution cannot be reached. An explicitly filtered LES approach can be used to mitigate this issue, and this is an area which needs further development. Last but not the least, the need to use fine grids when performing LES is of paramount importance, because, in LES, the subfilter field coincides with the subgrid field.

In the framework of TFNS, the filtered equations are established by applying a temporal filter to the exact form of the governing equations. The filter width does not relate to the time step of the numerical solution, and the eddy viscosity contains a so called filtering-control parameter, which is defined as the ratio of a (conceptual) temporal filter width to a characteristic integral time scale of the turbulent flow. Since the grid resolution and the model fidelity are not formally linked, in principle, a grid independent solution can be attained. It should be pointed out that TFNS is not LES, nor hybrid RANS/LES, nor, in general, unsteady RANS (URANS). When performing TFNS, grids must numerically support the spatial gradients of the filtered variables under investigation. Since the smoothness of these spatial gradients correlates to the value of the filtering-control parameter, requirement of grid sizes and distribution varies according to the specified value of the filtering-control parameter. This is a reflection of the characteristic of TFNS, i.e., the subfilter field is not the subgrid field.

This paper is organized as follows. In the next section, a description of the TFNS formulation for twophase flow and the subfilter closure models are presented. In Section 3.0, we describe an approximate evaluation of the filtered, chemical-reaction, source terms via a subgrid model of turbulence-chemistry interaction in the framework of TFNS. In Section 4.0, we summarize the experimental setup and the computation set up employed to assess the current, overall TFNS approach. This is followed by presenting some of the preliminary results in Section 5.0 and concluding remarks in Section 6.0.

\subsection{Mathematical Formulation}

The conservation equations for compressible reacting flow are solved using the TFNS approach. To simulate spray combustion, Lagrangian droplet model is concurrently solved with the Eulerian gas phase. In the following, we will briefly describe the definitions of time-filtered quantity, the gas-phase equations, and the coupling between the gaseous field and the spray field. We will then make a very general comment on the spray modeling without presenting the liquid-phase equations. 


\subsection{Time-Filtered Quantities $\bar{\phi}(x, t)$ and $\widetilde{\phi}(x, t)$}

In the case of compressible turbulent flow, we often use two distinct yet closely related time-filtered quantities. One is denoted by $\bar{\phi}(\boldsymbol{x}, t)$, which is defined as

$$
\bar{\phi}(\boldsymbol{x}, t)=\int_{-\infty}^{+\infty} \phi\left(\boldsymbol{x}, t^{\prime}\right) G\left(t-t^{\prime}\right) d t^{\prime}
$$

The integration is over the entire time domain $-\infty<t^{\prime}<+\infty$. Where $\phi$ is an unfiltered turbulent variable and $G\left(t-t^{\prime}\right)$ is a temporal filter with a constant filter width $\Delta_{T}$. Furthermore, this temporal filter satisfies the following conditions:

$$
\begin{gathered}
\int_{-\infty}^{+\infty} G\left(t-t^{\prime}\right) d t^{\prime}=1 \\
\int_{-\infty}^{+\infty} \phi\left(\boldsymbol{x}, t^{\prime}\right) G\left(t-t^{\prime}\right) d t^{\prime}=\phi(\boldsymbol{x}, t), \quad \text { as } \Delta_{T} \rightarrow 0
\end{gathered}
$$

The other filtered quantity is denoted by $\widetilde{\phi}(\boldsymbol{x}, t)$, which is defined as

$$
\widetilde{\phi}(x, t)=\frac{\overline{\rho \phi}}{\bar{\rho}}
$$

That is, $\widetilde{\phi}(\boldsymbol{x}, t)$ is determined by the familiar Favre filtering, which is density-weighted.

\subsection{Gas-Phase TFNS Equations}

Applying a temporal filter with a constant filter width to the exact equations of conservation of mass, momentum, energy, and chemical species, as well as the equation of state, the following filtered governing equations in the TFNS framework are obtained,

$$
\begin{gathered}
\frac{\partial \bar{\rho}}{\partial t}+\frac{\partial \bar{\rho} \widetilde{U}_{j}}{\partial x_{j}}=\tilde{\dot{\rho}}_{l i q} \\
\frac{\partial \bar{\rho} \widetilde{U}_{i}}{\partial t}+\frac{\partial}{\partial x_{j}}\left[\bar{\rho} \tilde{U}_{i} \tilde{U}_{j}+\bar{P} \delta_{i j}-\bar{\tau}_{i j}+\tau_{i j}^{s f c}\right]=\tilde{\dot{F}}_{i, l i q} \\
\frac{\partial \bar{\rho} \widetilde{E}}{\partial t}+\frac{\partial}{\partial x_{i}}\left[(\bar{\rho} \widetilde{E}+\bar{P}) \widetilde{U}_{i}+\bar{q}_{i}-\bar{\tau}_{i j} \widetilde{U}_{j}+E_{i}^{s f c}+I I_{i}^{s f c}+\sigma_{i}^{s f c}\right]=-S_{k}+\tilde{\dot{Q}}_{i, l i q} \\
\frac{\partial \bar{\rho} \widetilde{Y_{m}}}{\partial t}+\frac{\partial}{\partial x_{i}}\left[\bar{\rho} \widetilde{Y}_{m} \widetilde{U}_{i}-\bar{g}_{m i}+F_{m i}^{s f c}\right]=\bar{\rho} \tilde{S}_{m}+\tilde{\dot{\rho}}_{m, l i q} \\
\bar{P}=\bar{\rho} R_{u} \sum_{m=1}^{N_{s}} \frac{\tilde{Y}_{m} \tilde{T}_{m}}{M W_{m}}+\bar{\rho} R_{u} \sum_{m=1}^{N_{s}} T_{m}^{s f c}
\end{gathered}
$$


Where $\bar{\rho}$ is filtered mass density, $\tilde{U}_{i}$ is filtered velocity vector, $\bar{P}$ is filtered pressure determined from filtered equation of state, $\tilde{E}$ is filtered total energy per unit mass, $\bar{\tau}_{i j}$ is filtered viscous stress, $\bar{q}_{i}$ is filtered heat flux vector, and $S_{k}$ is the source term from the subfilter kinetic energy. In addition, $\tilde{Y}_{m}$ is filtered mass fraction of the $m$-th species, $\bar{g}_{m i}$ is filtered mass flux vector of $m$-th species. $\tilde{S}_{m}$ is the filtered reaction-source term of the m-th species, $M W_{m}$ is the molecular weight of the m-th species, $R_{u}$ is the universal gas constant, and $\tilde{T}$ is filtered temperature, $N_{s}$ is the total number of species. Subscripts 'liq' denote source terms from the liquid phase. Superscripts ' $s f c$ ' denote subfilter component (SFC) that require closure.

The filtered viscous stress tensor, filtered heat flux vector, and filtered mass flux vector of the m-th species are approximated as

$$
\begin{gathered}
\bar{\tau}_{i j}=2 \bar{\mu} \tilde{S}_{i j}-\frac{2}{3} \bar{\mu} \tilde{S}_{k k} \\
\bar{q}_{i}=-\bar{\kappa} \frac{\partial \widetilde{T}}{\partial x_{i}}-\sum_{m=1}^{N_{s}} \bar{\rho} \bar{D}_{m} \tilde{h}_{m} \frac{\partial \tilde{Y}_{m}}{\partial x_{i}}+\sum_{m=1}^{N_{s}} q_{i, m}^{s f c} \\
\bar{g}_{m i}=\bar{\rho} \bar{D}_{m} \frac{\partial \tilde{Y}_{m}}{\partial x_{i}}
\end{gathered}
$$

Where $\tilde{S}_{i j}$ is the filtered strain-rate tensor, and $\tilde{h}_{m}$ is the specific enthalpy of species $m$. Here, the molecular viscosity $(\bar{\mu})$ is approximated by the Sutherland's law based on filtered temperature $(\tilde{T})$, the thermal conductivity $(\bar{\kappa})$ and the diffusion coefficient of the $m$-th species are approximated as

$$
\begin{gathered}
\bar{\kappa}=\bar{\mu} \bar{c}_{p} / \operatorname{Pr} \\
\bar{D}_{m} \approx \frac{\bar{\mu}}{\bar{\rho} \mathrm{Sc}_{T}}
\end{gathered}
$$

Where $\bar{c}_{p}$ is the specific heat at constant pressure for the gaseous mixture, Pr is the Prandtl number, and $\mathrm{Sc}_{T}$ is the turbulent Schmidt number.

The SFC terms that require closure are

$$
\begin{gathered}
\tau_{i j}^{s f c} \equiv \bar{\rho}\left(\widetilde{U_{i} U_{j}}-\tilde{U}_{i} \tilde{U}_{j}\right) \\
q_{i, m}^{s f c} \equiv \overline{h_{m} D_{m} \frac{\partial Y_{m}}{\partial x_{i}}}-\tilde{h}_{m} \bar{D}_{m} \frac{\partial \tilde{Y}_{m}}{\partial x_{i}} \\
E_{i}^{s f c} \equiv \bar{\rho}\left(\widetilde{E U_{i}}-\tilde{E} \tilde{U}_{i}\right) \\
I I_{i}^{s f c} \equiv \overline{P U_{i}}-\bar{P} \tilde{U}_{i} \\
\sigma_{i}^{s f c} \equiv \widetilde{U_{j} \tau_{j i}}-\tilde{U}_{j} \bar{\tau}_{j i}
\end{gathered}
$$




$$
\begin{gathered}
F_{m i}^{s f c} \equiv \bar{\rho}\left(\widetilde{U_{i} Y_{m}}-\tilde{U}_{i} \tilde{Y}_{m}\right) \\
T_{m}^{s f c} \equiv \widetilde{Y_{m} T}-\tilde{Y}_{m} \tilde{T}
\end{gathered}
$$

In the present study, we neglect terms such as $q_{i, m}^{s f c}, I I_{i}^{s f c}$, and $T_{m}^{s f c}$. The closure of the rest of the SFC terms is described below.

\subsubsection{Momentum Transport Closure}

A general constitutive relationship between subfilter turbulent stresses and filtered strain rate (Ref. 1) leads to a nonlinear model for $\tau_{i j}^{s f c}$, i.e.,

$$
\begin{aligned}
\tau_{i j}^{s f c}= & -2 \bar{\rho} v_{T}\left(\tilde{S}_{i j}-\delta_{i j} \tilde{S}_{k k} / 3\right)+\frac{2}{3} \bar{\rho} k \delta_{i j} \\
& -A_{3} f \bar{\rho} \frac{k^{3}}{\varepsilon^{2}}\left(\tilde{S}_{i k} \tilde{\Omega}_{k j}-\tilde{\Omega}_{i k} \tilde{S}_{k j}\right) \\
& +2 A_{5} f \bar{\rho} \frac{k^{4}}{\varepsilon^{3}}\left[\tilde{\Omega}_{i k} \tilde{S}_{k j}^{2}-\tilde{S}_{i k}^{2} \tilde{\Omega}_{k j}+\tilde{\Omega}_{i k} \tilde{S}_{k m} \tilde{\Omega}_{m j}-\tilde{\Omega}_{k l} \tilde{S}_{l m} \tilde{\Omega}_{m k} \delta_{i j}+I I_{s}\left(\tilde{S}_{i j}-\delta_{i j} \tilde{S}_{k k} / 3\right)\right],
\end{aligned}
$$

where, $\tilde{S}_{i j}=\left(\widetilde{U}_{i, j}+\widetilde{U}_{j, i}\right) / 2, \quad \tilde{\Omega}_{i j}=\left(\widetilde{U}_{i, j}-\widetilde{U}_{j, i}\right) / 2, \quad I I_{s}=\left(\tilde{S}_{k k} \tilde{S}_{m m}-\tilde{S}_{k l} \tilde{S}_{l k}\right) / 2$. The model coefficients $C_{\mu}, A_{3}$ and $A_{5}$ are constrained by the realizability condition and the rapid distortion theory limit. They are formulated as (Ref. 2):

$$
C_{\mu}=\frac{1}{4.0+A_{s} \frac{k}{\varepsilon} U^{*}}, \quad A_{3}=\frac{\sqrt{1.0-A_{s}^{2} C_{\mu}^{2}\left(\frac{k}{\varepsilon} S^{*}\right)^{2}}}{0.5+1.5 \frac{k^{2}}{\varepsilon^{2}} \Omega^{*} S^{*}}, \quad A_{5}=\frac{1.6 C_{\mu} \bar{\rho} \frac{k^{2}}{\varepsilon}}{\bar{\rho} \frac{k^{4}}{\varepsilon^{3}} \frac{7 S^{*} S^{*}+\Omega^{*} \Omega^{*}}{4}},
$$

in which,

$$
\begin{gathered}
A_{s}=\sqrt{6} \cos \varphi, \quad \varphi=\frac{1}{3} \arccos \left(\sqrt{6} W^{*}\right), \quad W^{*}=\frac{S_{i j}^{*} S_{j k}^{*} S_{k i}^{*}}{\left(S^{*}\right)^{3}}, \\
U^{*}=\sqrt{\left(S^{*}\right)^{2}+\left(\Omega^{*}\right)^{2}}, \quad S^{*}=\sqrt{S_{i j}^{*} S_{i j}^{*}}, \quad \Omega^{*}=\sqrt{\tilde{\Omega}_{i j} \tilde{\Omega}_{i j}}, \quad S_{i j}^{*}=\tilde{S}_{i j}-\frac{1}{3} \delta_{i j} \tilde{S}_{k k}
\end{gathered}
$$

The coefficient $f$ is a function of the filtering-control parameter (FCP) which is defined as the ratio of a (conceptual) time filter width $\Delta_{T}$ to an integral time scale $T$, i.e., $\mathrm{FCP}=\Delta_{T} / T$. Furthermore (Ref. 3),

$$
f\left(\frac{\Delta_{T}}{T}\right) \approx 2\left(\frac{\Delta_{T}}{T}\right)-\left(\frac{\Delta_{T}}{T}\right)^{2}
$$

By definition, the value of the parameter FCP and the value of the coefficient $f$ are always between 0 and 1 .

This model uses the concept of subfilter eddy viscosity which is defined as 


$$
\begin{gathered}
v_{T}=f \cdot C_{\mu} \cdot k^{2} / \varepsilon \\
\mu_{T}=\bar{\rho} v_{T}
\end{gathered}
$$

Here, the subfilter turbulent kinetic energy and its dissipation rate $(k, \varepsilon)$ are determined from the following model equations:

$$
\begin{gathered}
\frac{\partial}{\partial t} \bar{\rho} k+\frac{\partial}{\partial x_{i}}\left[\bar{\rho} \tilde{u}_{i} k-\left(\bar{\mu}+\frac{\mu_{T}}{\sigma_{k}}\right) \frac{\partial k}{\partial x_{i}}\right]=S_{k} \\
\frac{\partial}{\partial t} \bar{\rho} \varepsilon+\frac{\partial}{\partial x_{i}}\left[\bar{\rho} \tilde{u}_{i} \varepsilon-\left(\bar{\mu}+\frac{\mu_{T}}{\sigma_{\varepsilon}}\right) \frac{\partial \varepsilon}{\partial x_{i}}\right]=S_{\varepsilon}
\end{gathered}
$$

where $\sigma_{k}$ and $\sigma_{\varepsilon}$ are model constants, the source terms are given by

$$
\begin{gathered}
S_{k}=-\tau_{i j}^{s f c} \tilde{s}_{i j}-\bar{\rho} \varepsilon \\
S_{\varepsilon}=-C_{\varepsilon 1} \tau_{i j}^{s f c} \tilde{s}_{i j} \frac{\varepsilon}{k}-C_{\varepsilon 2} \frac{\bar{\rho} \varepsilon^{2}}{k}
\end{gathered}
$$

where $C_{\varepsilon 1}$ and $C_{\varepsilon 2}$ are the model coefficients. We have adopted the commonly used values of $C_{\varepsilon 1}=1.45$ and $C_{\varepsilon 2}=1.92$ in the present work.

\subsubsection{Energy Transport Closure}

The subfilter total energy flux, $E_{i}^{s f c}$, is also modeled using the subfilter eddy viscosity and gradient assumption, a nonlinear model is formulated as (Ref. 2)

$$
E_{i}^{s f c}=-\kappa_{T} \frac{\partial \tilde{T}}{\partial x_{i}}-\frac{\mu_{T}}{\bar{\rho}} \frac{1}{\operatorname{Pr}_{T}} \frac{k}{\varepsilon}\left(c_{1} \tilde{S}_{i j}+c_{2} \tilde{\Omega}_{i j}\right) \frac{\partial \bar{\rho} \bar{c}_{\mathrm{v}} \tilde{T}}{\partial x_{j}}
$$

Here, $\operatorname{Pr}_{T}$ is the turbulent Prandtl number, $\bar{c}_{\mathrm{v}}$ is the specific heat at constant volume for the gaseous mixture. The coefficients $c_{1}$ and $c_{2}$ are yet to be calibrated. In the current simulations they are set to be $c_{1}=c_{1}=-0.24$. The subfilter thermal conductivity $\left(\kappa_{T}\right)$ is evaluated by

$$
\kappa_{T}=\mu_{T} \bar{c}_{p} / \operatorname{Pr}_{T}
$$

It is noted here that the total energy $(\tilde{E})$ is evaluated as

$$
\tilde{E}=\tilde{e}+\frac{1}{2} \tilde{U}_{i} \tilde{U}_{i}
$$

where $\tilde{e}$ is the specific internal energy of the mixture. The subfilter viscous work is modeled as

$$
\sigma_{i}^{s f c}=\tilde{U}_{j} \tau_{j i}^{s f c}
$$




\subsubsection{Species Transport Closure}

Similar to the subfilter total energy flux, the subfilter mass flux of $m$-th species is modeled as

$$
F_{m i}^{s f c}=-\bar{\rho} D m_{T} \frac{\partial \tilde{Y}_{m}}{\partial x_{i}}-D m_{T} \frac{k}{\varepsilon}\left(c_{1} \tilde{S}_{i j}+c_{2} \tilde{\Omega}_{i j}\right) \frac{\partial \bar{\rho} \tilde{Y}_{m}}{\partial x_{j}}
$$

with

$$
D m_{T}=\frac{\mu_{T}}{\bar{\rho} S c_{T}}
$$

where $\mathrm{Sc}_{T}$ is turbulent Schmidt number.

In the present study, the filtered reaction rate of $m$-th species $\left(\tilde{S}_{m}\right)$ is approximately evaluated via a subgrid model of turbulent mixing and combustion, and this model is described in Section 3.0.

\subsection{Coupling between Gaseous Field and Spray Field}

This coupling is through the interphase exchange terms. The effects of the spray field on the gaseous field are accounted for by the source terms from the liquid phase in the gas-phase equations (Eqs. (5), (6), (7), and (8)), and they are modeled as (Ref. 4)

$$
\begin{gathered}
\tilde{\dot{\rho}}_{l i q}=\frac{1}{V_{c}} \sum_{k} n_{k} \dot{m}_{k} \\
\tilde{\dot{F}}_{i, l i q}=\frac{1}{V_{c}} \sum_{k} n_{k}\left(\dot{m}_{k} u_{k i}-\frac{4 \pi}{3} \rho_{k} r_{k}^{3} \frac{d u_{k i}}{d t}\right) \\
\tilde{\dot{Q}}_{l i q}=\frac{1}{V_{c}} \sum_{k} n_{k} \dot{m}_{k}\left(h_{s}-\ell_{k, \text { eff }}\right) \\
\tilde{\dot{\rho}}_{m, l i q}=\frac{1}{V_{c}} \sum_{k} \varepsilon_{m} n_{k} \dot{m}_{k}
\end{gathered}
$$

where $V_{c}$ is the volume of the computational cell, $n_{k}$ is the number of droplets in $k$-th drop group, $\dot{m}_{k}$ is the vaporization rate of droplets in $k$-th group, $u_{k i}$ is the $i$-th velocity component of $k$-th group, $\rho_{k}$ is the density of droplets in $k$-th group, $r_{k}$ is the droplet radius in $k$-th group, $h_{s}$ is the specific enthalpy at the droplet surface, $\ell_{k \text {,eff }}$ is the effective latent heat of vaporization of droplets in $k$-th group, and $\varepsilon_{m}$ is the fractional vaporization rate for species $\mathrm{m}$.

\subsection{Liquid-Phase Modeling}

The governing equations of the liquid phase are based on a Lagrangian formulation where the spray particle position and velocity are described by a set of ordinary differential equations. Various submodels, such as the droplet drag model and the drop vaporization model, are needed to simulate the transport of a vaporizing spray particle. The specification of the fuel injection condition plays a major role in the fidelity of the simulation. Common practice is to specify the starting droplet condition using correlations of droplet sizes calibrated by relevant experimental data. In addition to the use of correlation, various 
models for primary atomization and secondary droplet breakup also have been employed. A more detailed description of the liquid phase modeling and the two-way coupling between the liquid-phase and gasphase transport can be found in Reference 4.

\subsection{Subgrid Model of Mixing and Combustion}

Simulation of turbulent combustion requires modeling the turbulence-chemistry interaction processes. To this end, various approaches have been invoked in many previous studies. Examples of these approaches include the so-called unmixed model, eddy-break-up model, thickened flame model, flameletbased method, conditional moment closure method, filtered mass density function/probability density function method, and linear-eddy mixing (LEM) model. In the present study, we focus on the LEM model, because it does not treat molecular mixing and small scale turbulence effects as a single process (micro mixing), and it can be applied to both nonpremixed and premixed burning. The major drawback of this model is its relatively high computational cost which can be very high when detailed chemical kinetics is employed. A fairly detailed description of the LEM model when used in the LES framework can be found in Reference 5 .

Closely following the approach described in Reference 5, we have adapted the LEM model into the TFNS framework, and we call it LEM-like to emphasize that (i) instead of using LEM model to directly establish the entire species field without actually solving filtered equations of species, the LEM model is used locally (both in space and time) to only provide approximations of filtered reaction source terms in the filtered equations of the species to be solved, (ii) instead of solving unfiltered quantities using the LEM equations, the same forms of the LEM equations are employed as a subgrid model of mixing and combustion of time-filtered scalars, with the molecular transport coefficients substituted by the 'effective' transport coefficients.

The LEM-like model is implemented in terms of a fractional splitting technique; it is divided into a supergrid process and a subgrid process. The supergrid process emulates the convection of the scalar field by grid-resolved velocity field across the surfaces of the computational cell. The subgrid process, which occurs within each computational cell, consists of four operators: (a) (effective) molecular diffusion, (b) finite-rate chemical reaction, (c) volumetric expansion caused by the heat release, and (d) stochastic stirring due to the subgrid eddies.

\subsection{Supergrid Process}

The macro mixing of the scalars is implemented by a Lagrangian transfer of LEM elements across the surfaces of the CFD computational cells. This Lagrangian transport is also known as splicing. Referring to Figure 1, for example, the outward mass through the right side of a cell computed from filtered velocity and density is equivalent to 1.5 LEM elements and colored in red. The outward mass through the bottom side of the mesh is equivalent to 2.5 LEM elements and colored in magenta. Similarly, the inward mass through the top and left sides of the mesh are equivalent to 6 LEM elements. Splicing will result in 14 LEM elements in this computational cell. In general, splicing will cause different computational cell to have different number of LEM elements. To avoid programming complexities in a parallel environment, the LEM domain is re-gridded to have the same fixed number of elements, and each element is of the same volume. Conservation of mass is maintained during the re-gridding procedure. 


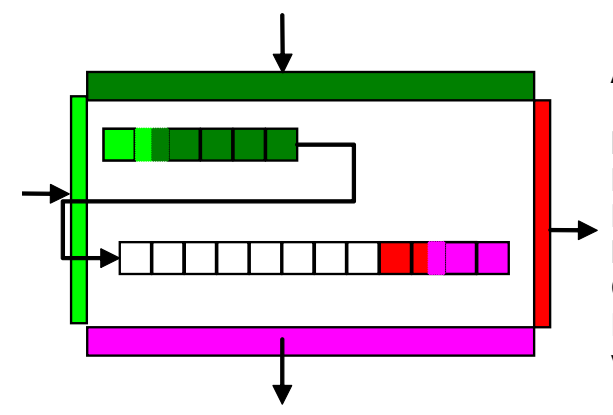

Arrows -- Convection direction

Initial number of lumps - 12

Light Green - inward mass (1.5)

Dark Green - inward mass (4.5)

Red - outward mass (1.5)

Magenta - outward mass (2.5)

Current number of lumps -- 14

Final number of lumps will became 12 after re-gridding

via equalizing the volume.

Figure 1.-Schematic illustrating the splicing algorithm used for scalar convection. (Assuming the number of LEM elements is 12. Each element carries its own volume, filtered temperature, and filtered species density).

\subsection{Subgrid Process}

Within each CFD computational cell, a one-dimensional domain consisting of a fixed number of LEM elements is employed, the governing equations have the following form:

$$
\begin{gathered}
\bar{\rho} \frac{\partial \tilde{Y}_{m}}{\partial t}=F_{\tilde{Y}_{m}, s t i r r i n g}+\frac{\partial}{\partial s}\left(\bar{\rho} D_{m, e f f} \frac{\partial \tilde{Y}_{m}}{\partial s}\right)+\bar{\rho} \dot{\omega}_{m}\left(\tilde{Y}_{1}, \tilde{Y}_{2}, \cdots, \tilde{Y}_{N_{s}}\right) \\
\overline{\rho c_{p}} \frac{\partial \tilde{T}}{\partial t}=F_{\tilde{T}_{, \text {stirring }}}+\sum_{m=1}^{N_{s}}\left(\bar{\rho}_{p m} D_{m, e f f} \frac{\partial \tilde{Y}_{m}}{\partial s} \frac{\partial \tilde{T}}{\partial s}\right)+\frac{\partial}{\partial s}\left(\kappa_{e f f} \frac{\partial \tilde{T}}{\partial s}\right)-\sum_{m=1}^{N_{s}} \tilde{h}_{m} \dot{\omega}_{m}
\end{gathered}
$$

where $F_{\tilde{Y}_{m} \text {,stirring }}$ and $F_{\tilde{T}_{\text {,stirring }}}$ represent the subgrid turbulent mixing, and they are accounted for by employing a stochastic rearrangement of the LEM elements, known as the triplet mapping, more details about this mapping procedure can be found in Reference 5 . Here, $\mathrm{D}_{m, e f f}$ is the effective mass diffusion coefficient, $\kappa_{\text {eff }}$ is the effective heat conductivity, and $\dot{\omega}_{m}\left(\tilde{Y}_{1}, \tilde{Y}_{2}, \cdots, \tilde{Y}_{N_{s}}\right)$ indicates that the reaction kinetics of unfiltered species mass fractions is formally used for the reaction kinetics of filtered species mass fractions.

The solution of the above one-dimensional LEM-like equations over NLEN elements gives a subgrid field of $\tilde{Y}_{m}$, namely, $\tilde{Y}_{m}^{l=1}, \tilde{Y}_{m}^{l=2}, \cdots, \tilde{Y}_{m}^{l=N L E N}$. Their average, $\tilde{Y}_{m}^{L E M}(t+\Delta t)$, provides a prediction of $\tilde{Y}_{m}(t+\Delta t)$ at the center of the computational cell. This predicted value is then used to construct an approximation of the filtered source term $\left(\tilde{S}_{m}\right)$ needed to solve Equation (8). In the current study, the approximation is

$$
\tilde{S}_{m}=\frac{\tilde{Y}_{m}^{L E M}(t+\Delta t)-\tilde{Y}_{m}^{T F N S}(t)}{\Delta t}
$$

where $\tilde{Y}_{m}^{T F N S}(t)$ is the TFNS solution of the (filtered) species mass fraction at the computational cell center. 


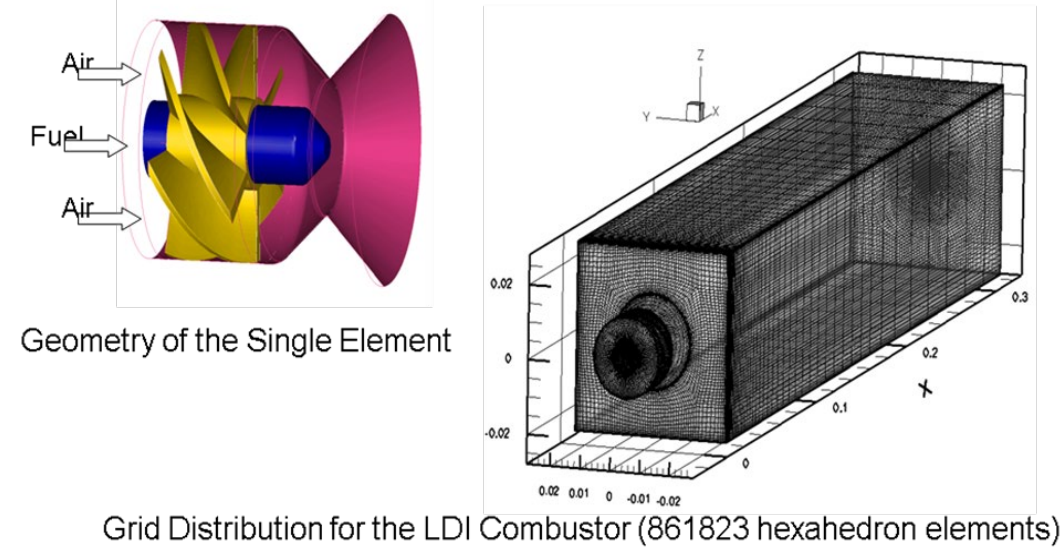

Figure 2.-Swirler geometry and computational domain of a single-element LDI combustor.

\subsection{Experimental and Computational Setup}

Target application is low-emissions, fuel-flexible combustors, including the lean-direct-injection (LDI) combustors. A typical single-element LDI combustor is illustrated in Figure 2. More detailed description of the combustor geometry and the test rig can be found in Reference 6 . Each element consists of an air passage with an upstream air swirler and a converging-diverging venturi section. The fuel is injected through the center of swirler and the fuel tip is at the throat of the venture. The air swirlers have six helical, axial vanes with downstream vane angles of $60^{\circ}$. The air then dumps into a combustion chamber with a square cross-section. Velocity measurements were taken with a two-component Laser Doppler Velociometry (LDV) system, temperature measurements were taken with thermocouples, and emissions data was gathered via an isokinetic probe and gas analyzer. Quartz makes up the combustion section. In regions close to the dump plane, measured gas-phase velocities may suffer from some contamination by the injected spray. The combustor experiments also may have significant convective and radiation heat losses. The temperature measurements reported are not corrected to adiabatic conditions. Experimental droplet measurements are collected with a Phase Doppler Particle Analyzer (PDPA).

The computational domain consists of approximately 862,000 hexahedral elements (see Figure 2). At the air inflow boundary, the air flow speed is $20.14 \mathrm{~m} / \mathrm{s}$, the density is $1.19 \mathrm{~kg}$ per cubic meter, and the static temperature is $294.28{ }^{\circ} \mathrm{K}$. The operating pressure of the combustor is approximately $1 \mathrm{~atm}$, and the measured pressure drop (as a percentage of the air inlet pressure) during the experiments was measured at $4 \%$. At the combustor chamber exit, an outlet boundary condition facilitating the convection of pressure disturbances out of the computational domain is applied.

The fuel is injected at $0.415 \mathrm{~g} / \mathrm{s}$, which gives a global equivalence ratio of 0.75 . The specification of the starting condition for the fuel spray is particularly critical for accurate predictions. In this study, the following droplet size distribution is used (Ref. 4):

$$
\frac{d n}{n}=4.21 \times 10^{6}\left[\frac{d}{d_{32}}\right]^{3.5} e^{-16.98\left(\frac{d}{d_{32}}\right)^{0.4}} \frac{d d}{d_{32}}
$$

where $n$ is the total number of the droplets and $d n$ is the number of droplets in the size range between $d$ and $d+d d$. This correlation also requires the specification of a Sauter mean diameter, $d_{32}$ and the number of droplet classes. These specified inflow droplets will undergo evaporation without secondary breakup. Experimental data suggests a Sauter mean diameter around $32 \mu \mathrm{m}$, and the spray cone angle is $90^{\circ}$. 
In this study, the liquid fuel $\mathrm{C}_{12} \mathrm{H}_{23}$ is used as the surrogate for the experimental Jet-A fuel, and a single-step, five-species global reduced mechanism (see e.g., Ref. 7) is employed for the chemical reactions (Table I).

TABLE I.-SINGLE STEP (GLOBAL) CHEMISTRY MODEL

\begin{tabular}{|c|l|c|c|c|}
\hline \multicolumn{1}{|c|}{ Reaction } & \multicolumn{1}{|c|}{$\mathrm{A}$} & $\mathrm{n}$ & $\begin{array}{c}\mathrm{E} \\
\text { cal } / \text { mole }\end{array}$ \\
\hline 1 & $\begin{array}{l}4 \mathrm{C}_{12} \mathrm{H}_{23}+71 \mathrm{O}_{2}=>48 \mathrm{CO}_{2}+46 \mathrm{H}_{2} \mathrm{O} \\
\mathrm{GLO} / \mathrm{C}_{12} \mathrm{H}_{23} 0.10 / \\
\mathrm{GLO} / \mathrm{O}_{2} 1.65 /\end{array}$ & $8.60 \times 10^{11}$ & 0.00 & $3.00 \times 10^{4}$ \\
\hline
\end{tabular}

The current TFNS (with FCP $=0.255$ ) solutions are obtained by an iteratively implicit, finite-volume scheme that is second-order accurate in space and time. The LEM-like equations are solved using a standard fractional splitting, finite-difference scheme, and 24 LEM elements per CFD computational cell are employed.

\subsection{Results}

While recognizing that the inherent uncertainties in current models of liquid fuel atomization, fuel evaporation, and fuel chemistry often can be overwhelming, this LDI burner and its measured data has been used to assess as well as guide the development of modeling and simulation of two-phase turbulent combustion in LDI combustors. Results from RANS approach are reported in Reference 7. Results from LEM-LES approach are presented in Reference 5, and results from flamelet-LES approach are described in Reference 8. In the following, some of the results obtained from the TFNS approach are presented.

The results of non-reacting flow and the comparison with experimental data can be found in Reference 9. They reveal the major flow structures in the LDI combustor. Figure 3 is a snapshot of the unsteady flow field. Embedded in this figure are the instantaneous iso-surface of the zero axial velocity component colored by the effective eddy viscosity and six instantaneous stream lines emanating from the upstream of the swirler, going through the converging-diverging nozzle, then passing through the combustion chamber. Major flow structures in the LDI combustor are visualized via the iso-surface of the zero axial velocity and the iso-surface of a relatively low pressure. The iso-surface of the zero axial velocity is also known as the vortex-breakdown bubble (VBB). The iso-surface of a sufficiently low pressure captures the precessing-vortex core (PVC). Figure 4 is a snapshot of the PVC and VBB. The dark blue region is a vortex core, which is formed near the venturi throat and extends into the combustor chamber. This spiraling vortex core rotates and breaks, it changes randomly in space and time. The light green surfaces are the iso-surfaces of the zero axial velocity. In addition to the VBB, there are some small structures near the dump plane and in the corner region. Figure 5 shows the instantaneous streamlines around the PVC, they start from the upstream of the swirler, and yield a complex, seemingly random pattern. Some of them spiral around the dark blue surface indicating that the dark blue region is indeed a vortex core. As demonstrated in Reference 5, the dynamics of the PVC and the VBB, as well as their interactions, are critical to the fuel-air mixing and the flame stability in the LDI combustors. 


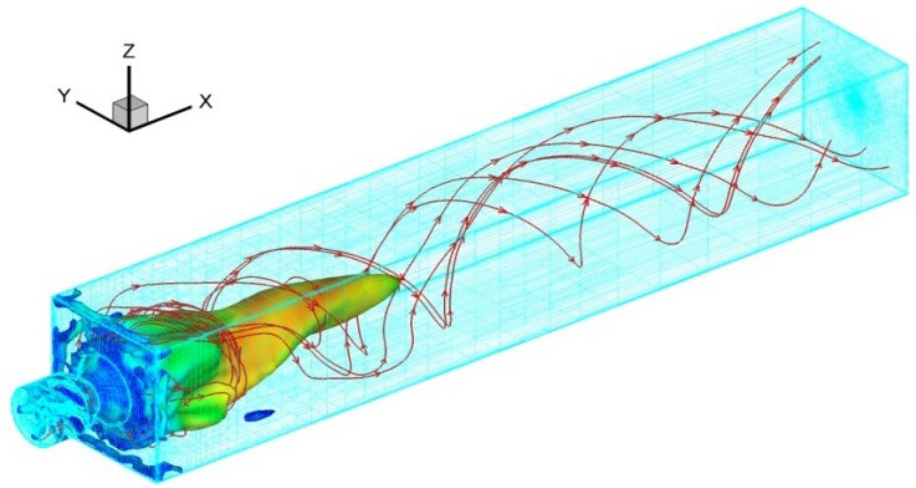

Figure 3.-A snapshot of the unsteady flow field.
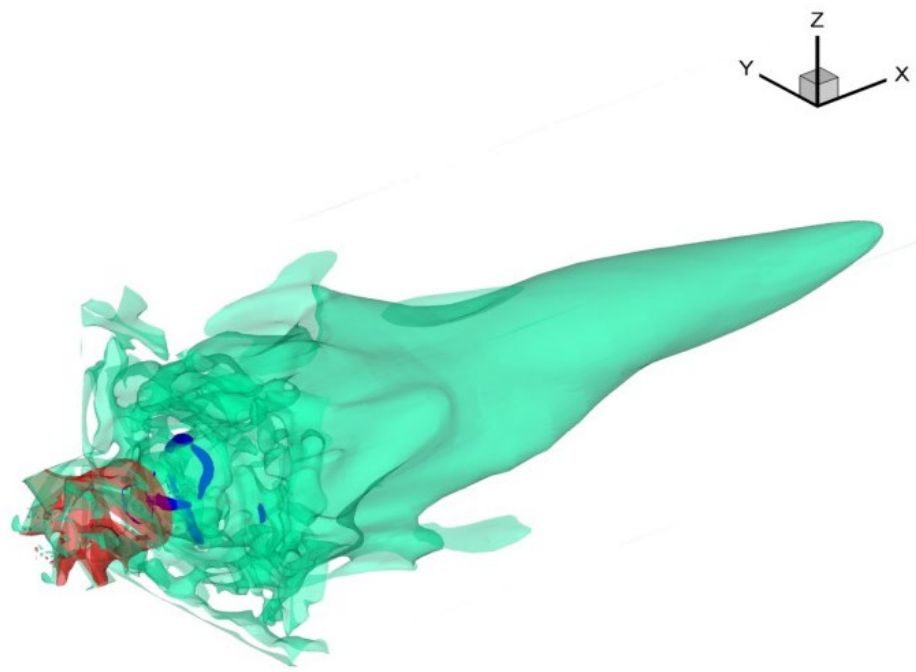

Figure 4.-A snapshot of precessing-vortex core (PVC) and vortex-breakdown bubble (VBB).

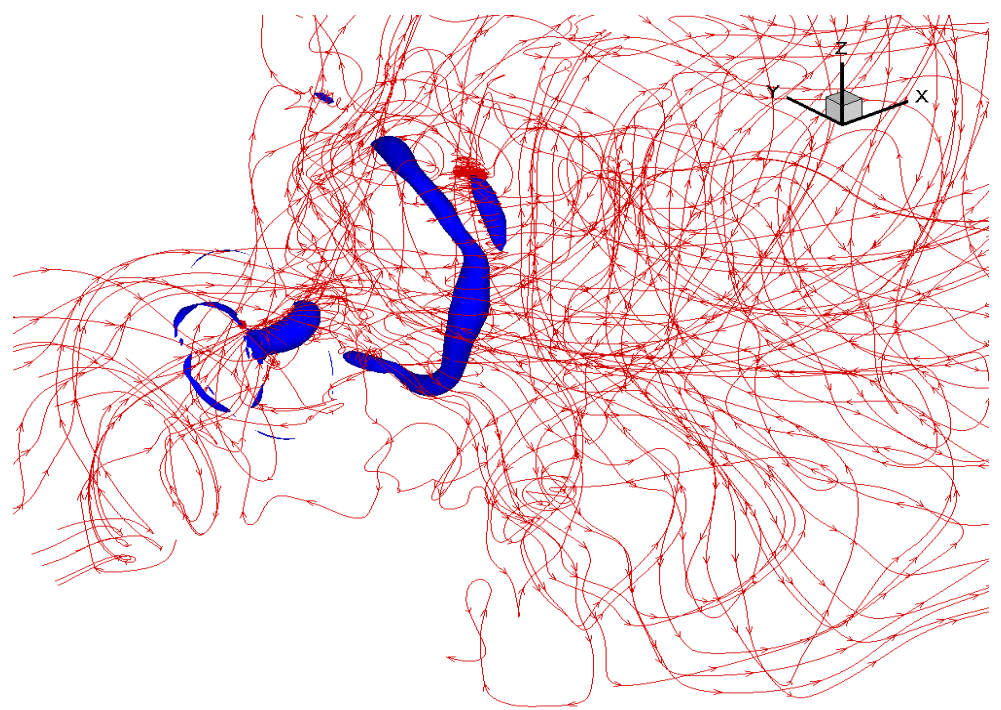

Figure 5.-Instantaneous streamlines around the precessingvortex core (PVC). 
The same grid is used for the two-phase reacting flow calculations. Figure 6 is a snapshot of the spray droplet field. The performance of the LEM-like model is highlighted in terms of the calculated temperature field. The comparison between the temperature field from the LEM-like model and the temperature field from the so-called unmixed (umx) model is shown in Figure 7. The unmixed model neglects the direct effects of turbulent fluctuations when evaluating the filtered reaction source terms in the species equations. The temperature field shown in Figure 7 is averaged temperature in the center plane $(\mathrm{z}=0)$. In the unmixed case, the filtered temperature is averaged over 10,000 time-steps (i.e., $0.01 \mathrm{sec})$. In the LEM-like case, the filtered temperature is averaged over 5,000 time-steps (i.e., $0.005 \mathrm{sec}$ ). The feature of the temperature field calculated by using the LEM-like model is closer to what is typically observed in the experiments than the one from the unmixed model.

Figure 8 is the (gage) pressure trace recorded at a centerline point which is $15 \mathrm{~mm}$ downstream of the dump plane having a cross-section of $25.4-$ by $25.4-\mathrm{mm}$. In the following, time-averaged quantities are presented. The time period used to construct these averages is from time-step 380,001 to time-step 500,000 , and the corresponding duration is $0.12 \mathrm{sec}$. All contour plots illustrate the distributions in the center plane $(\mathrm{z}=0)$. Time-average of filtered temperature is shown in Figure 9, also included are two snapshot solutions. Similarly, time-average of filtered fuel $\left(\mathrm{C}_{12} \mathrm{H}_{23}\right)$ vapor mass fraction, along with two snapshot solutions, are given in Figure 10. Time-averaged field gives the impression of an orderly, symmetric burning, the snapshots suggest that, in parts of the flame region, the supply of fuel vapor is intermittent, and pockets of significant temperature variation exist.

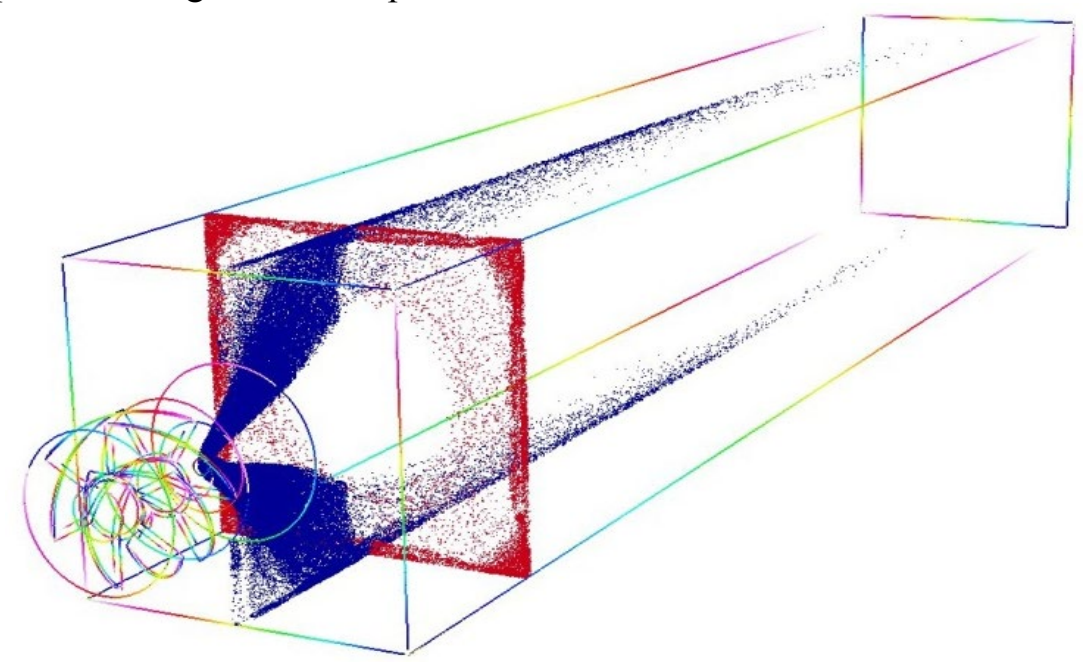

Figure 6.-A snapshot of the spray-droplet distribution in the center plane and a cross-section.

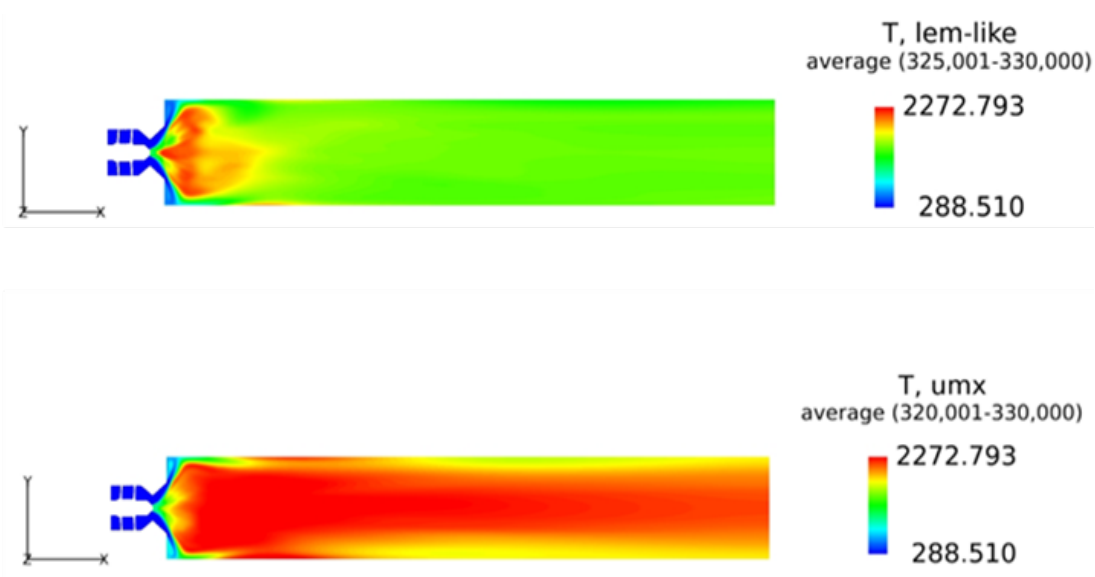

Figure 7.-Temperature field in the center plane $(z=0)$. 


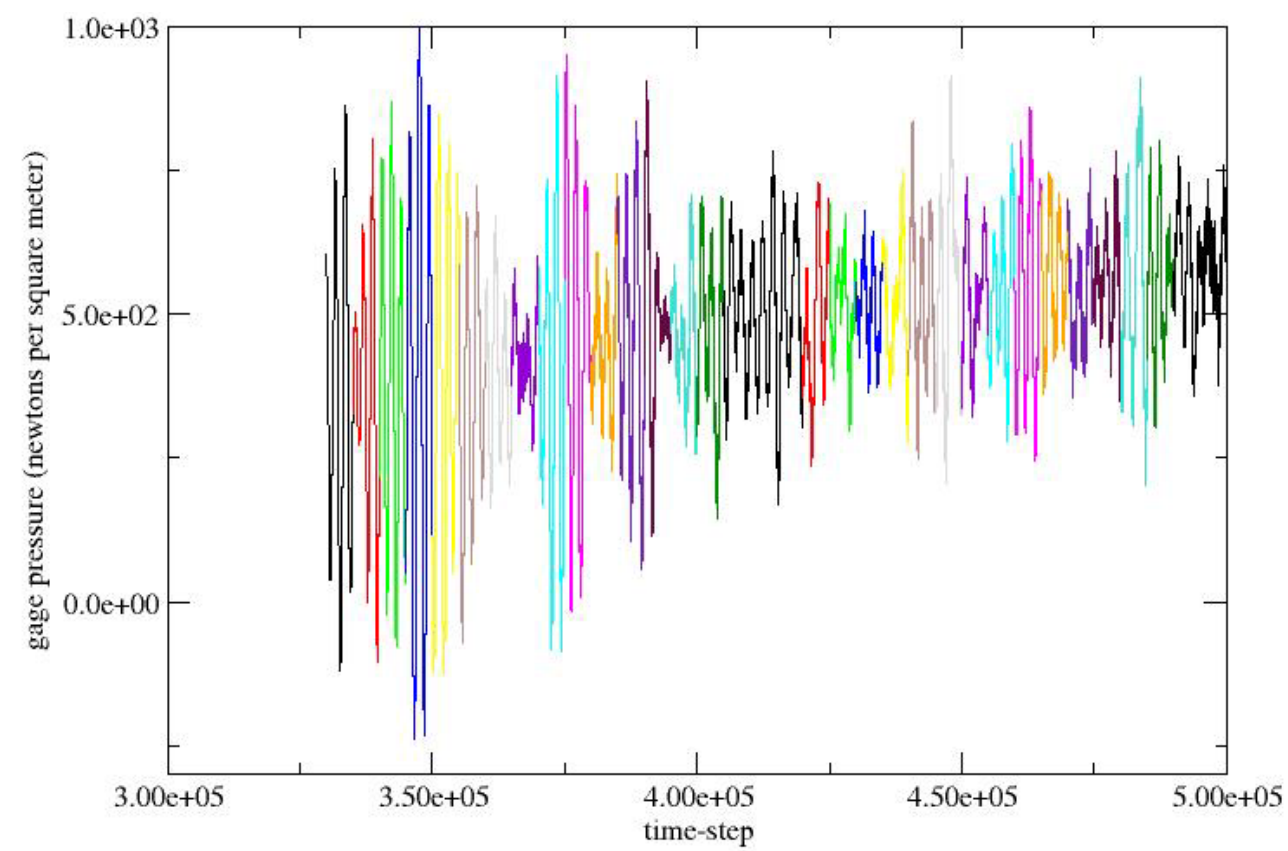

Figure 8.-Pressure trace at a center point which is $15 \mathrm{~mm}$ downstream of the dump plane.

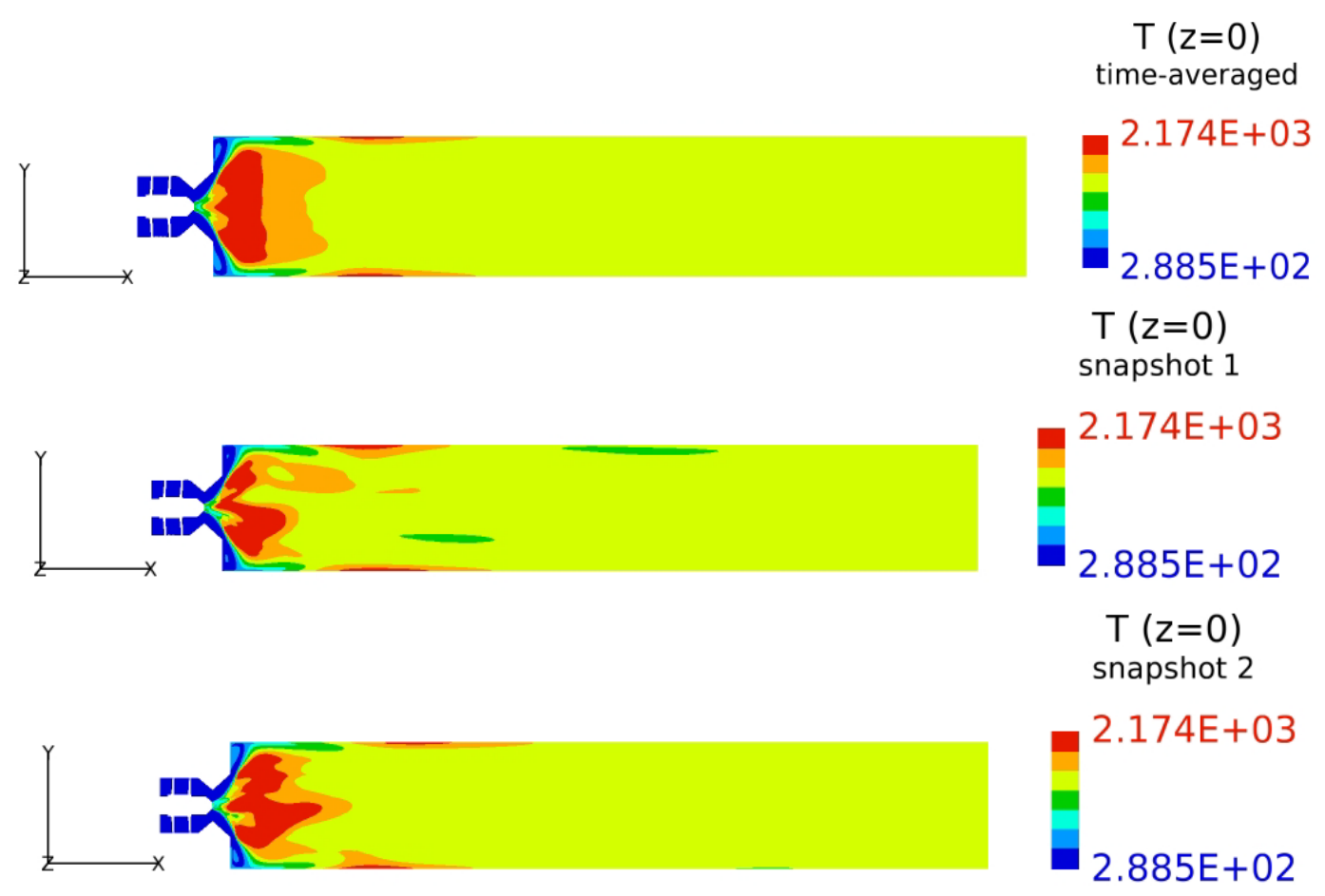

Figure 9.-Temperature distribution in the center plane: time-averaged field and two snapshots. 


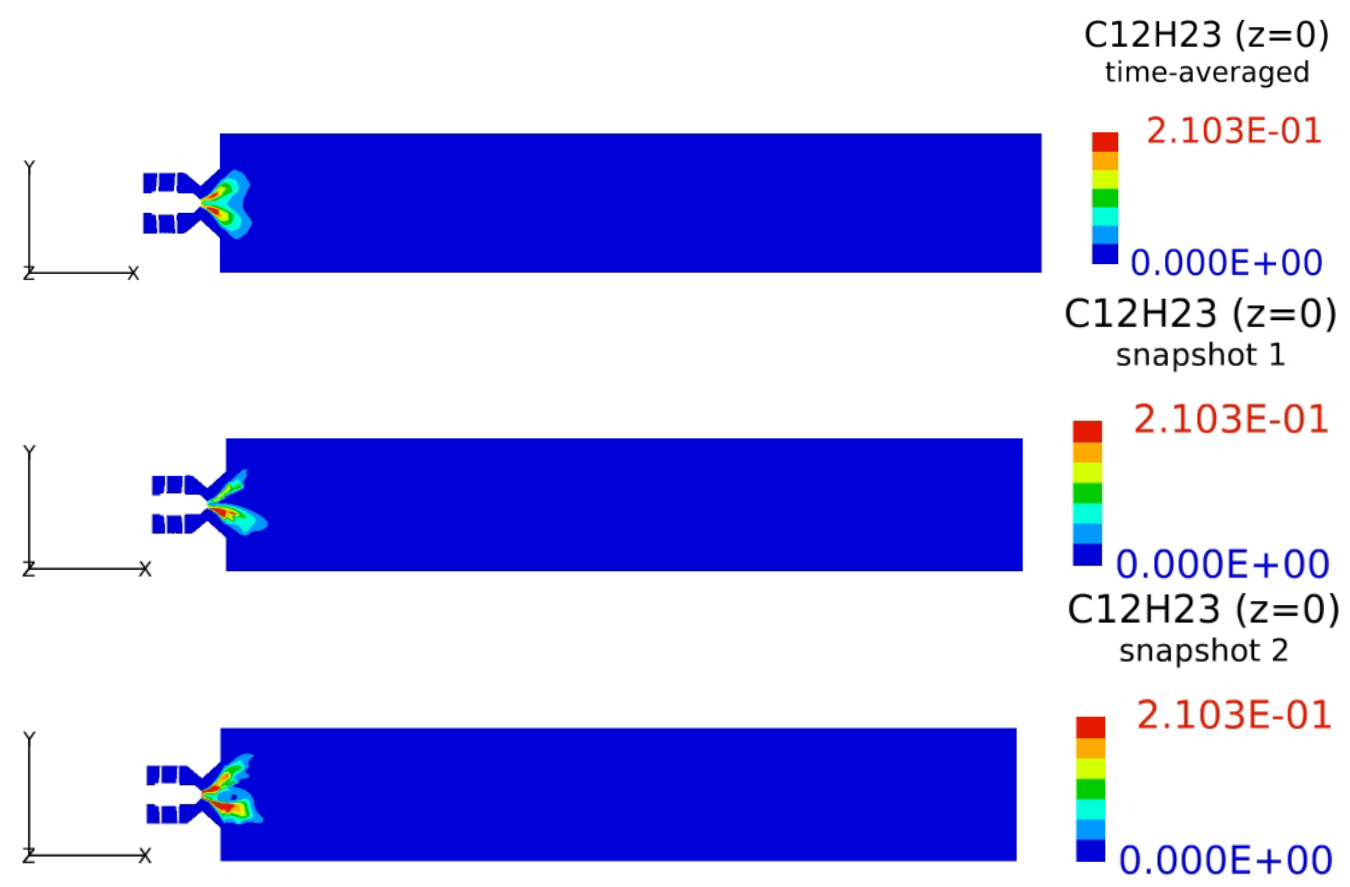

Figure 10.-Fuel vapor distribution in the center plane: time-averaged field and two snapshots.

In the following, comparisons between time averages of filtered quantities and experimental mean values are shown. The discrepancies may be due to a variety of reasons. In addition to the obvious computational reasons such as grid resolution, there are model-related causes, and we will, based on information available to us from other closely related studies, suggest some of these possible causes without discussion.

Centerline averaged temperature downstream of the dump plane (located at $\mathrm{x}=0.0072 \mathrm{~m}$ ) along the length of the combustor is shown in Figure 11. Near the dump plane, the major cause of the discrepancy is the spray injection and vaporization models, the discrepancy in the downstream region is mainly due to the employed subgrid model of turbulent mixing. Figure 12 presents the centerline averaged axial velocity along the combustor length. In the immediate neighborhood of the dump plane, there was difficulty in sorting seeder particles from high-momentum spray particles in the experimental study; nevertheless, heat-release tied to the spray models is also a cause of the discrepancy. These possible causes of discrepancies between computational averages and experimental mean values also are the possible reasons for discrepancies shown in Figure 13 and Figure 14. Figure 13 is the radial profile of the averaged temperature at $5 \mathrm{~mm}$ downstream of the dump plane, and Figure 14 is the radial profile of the averaged axial velocity at $5 \mathrm{~mm}$ downstream of the dump plane. Note that similar discrepancies relative to experiments have been reported in Reference 8 . The radial profile of the averaged azimuthal velocity at this location is presented in Figure 15. It suggests the need of improved grid resolution in the crosssection. 


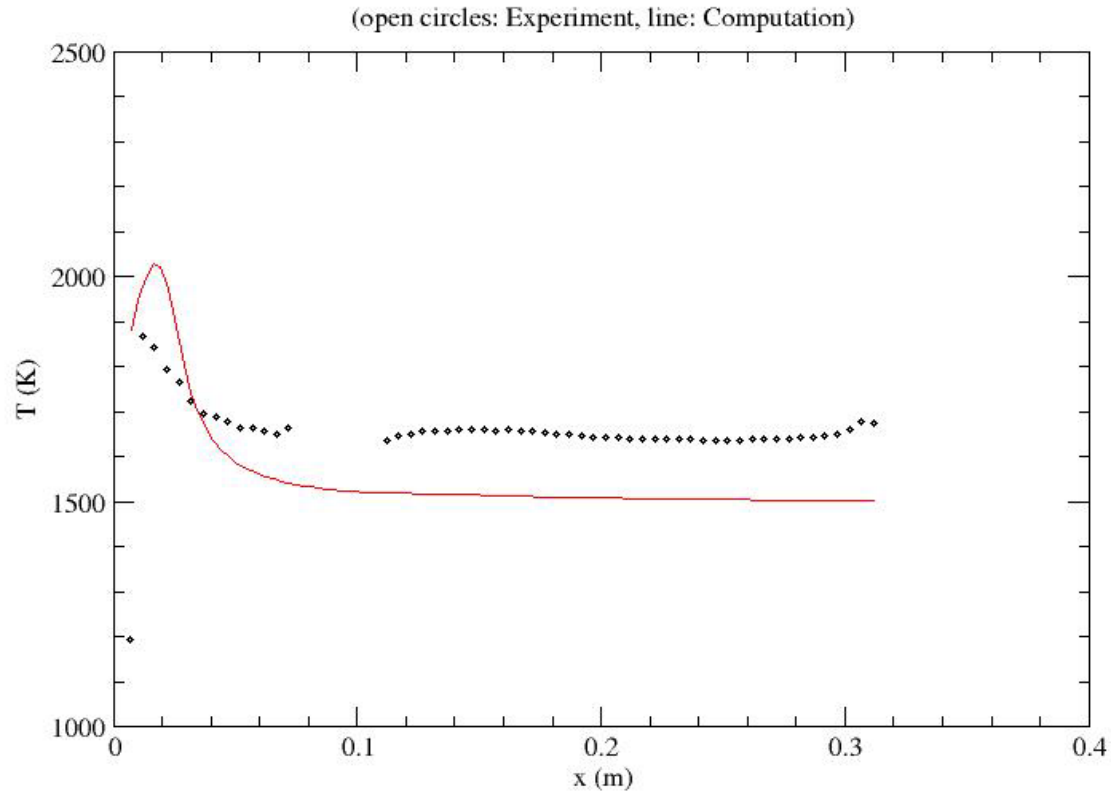

Figure 11.-Averaged temperature along the center line.

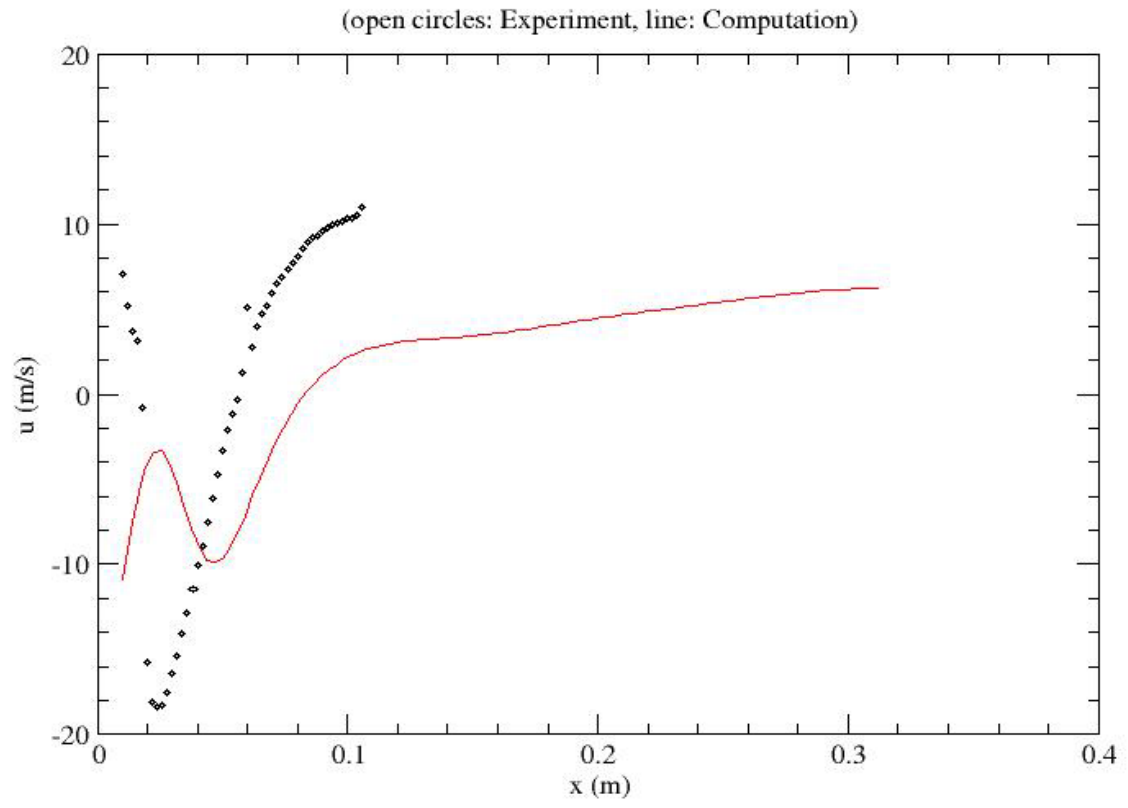

Figure 12.-Averaged axial velocity along the center line. 


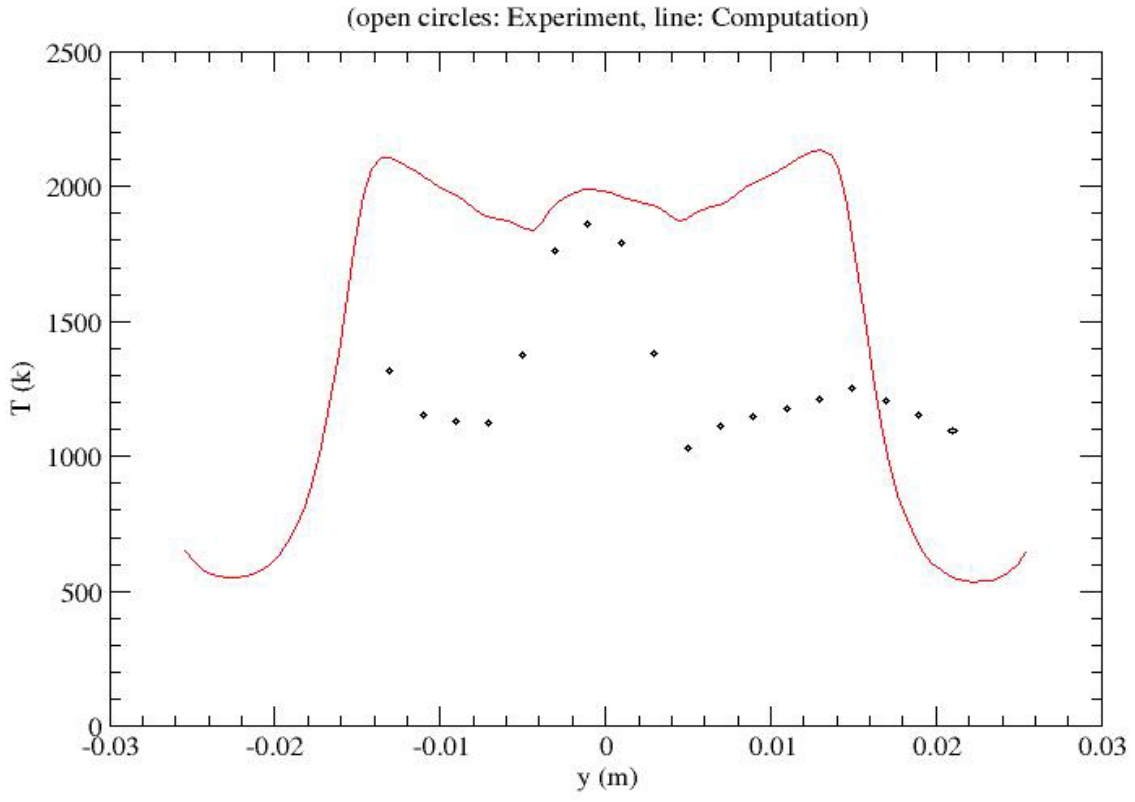

Figure 13.-Radial profile of averaged temperature $(5 \mathrm{~mm}$ downstream of the dump plane).

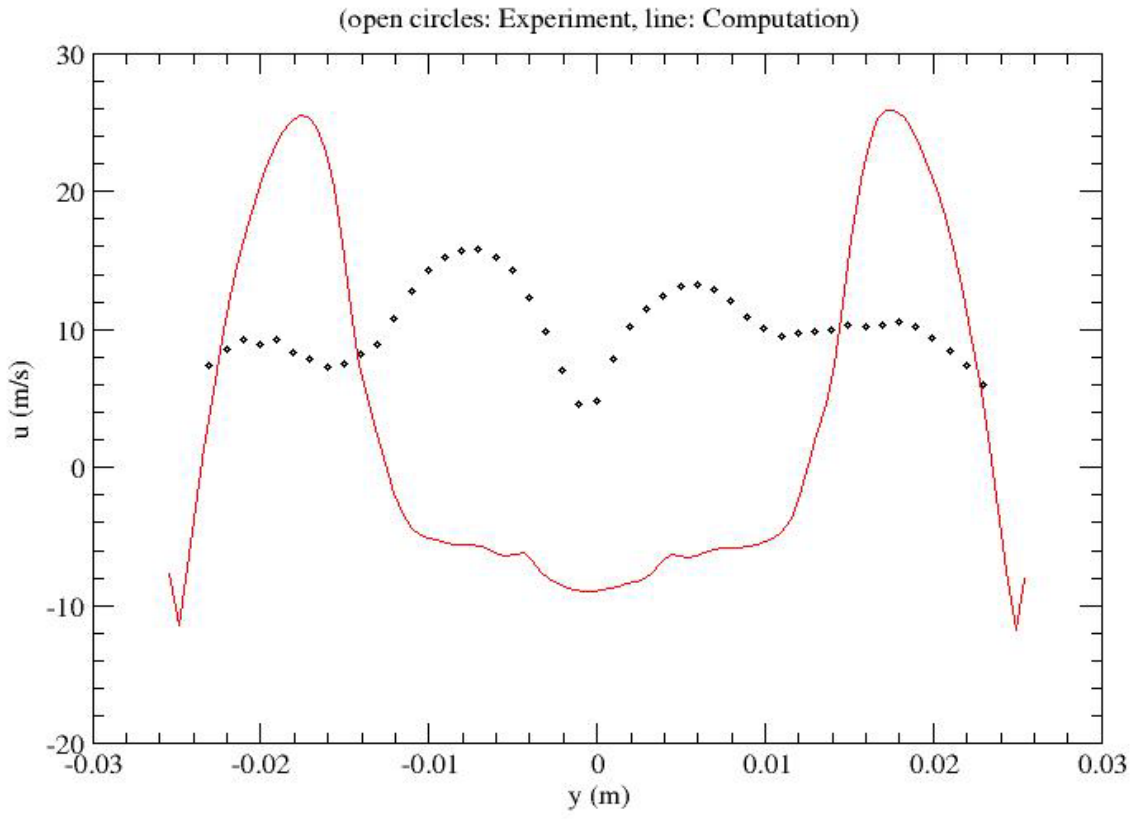

Figure 14.-Radial profile of averaged axial velocity ( $5 \mathrm{~mm}$ downstream of the dump plane). 


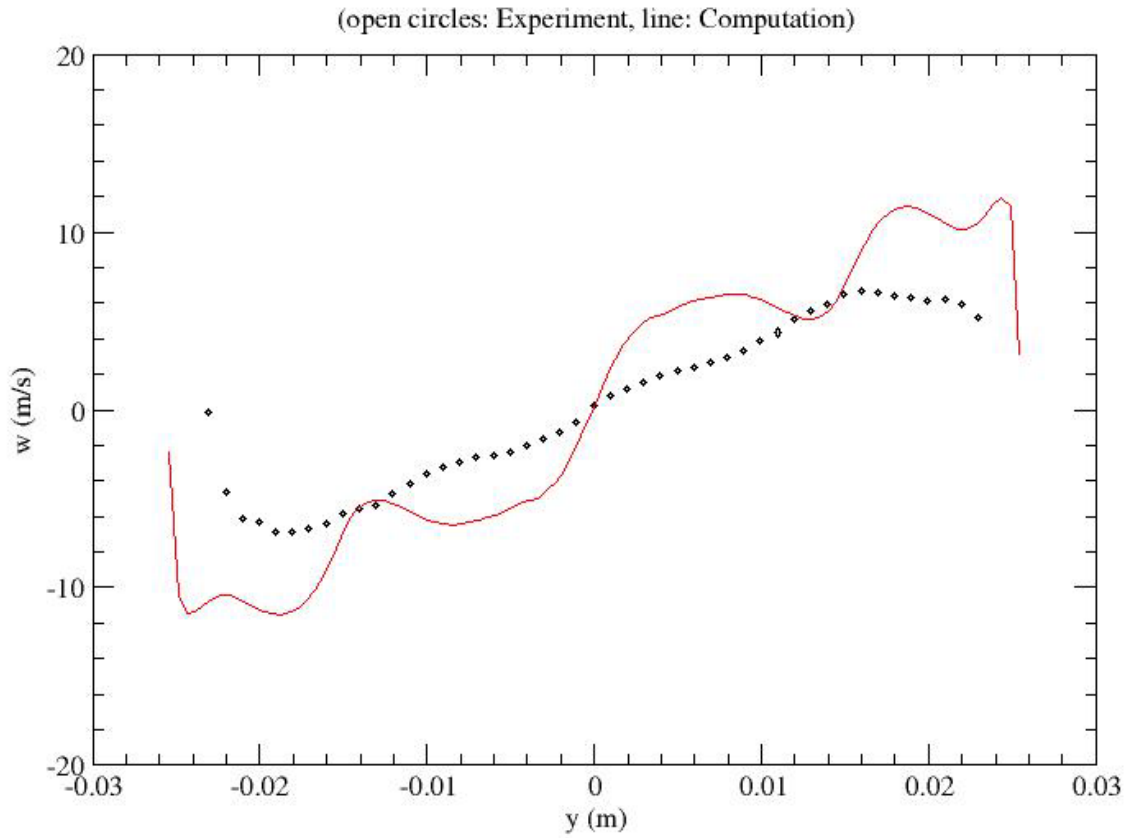

Figure 15.-Radial profile of averaged azimuthal velocity $(5 \mathrm{~mm}$ downstream of the dump plane).

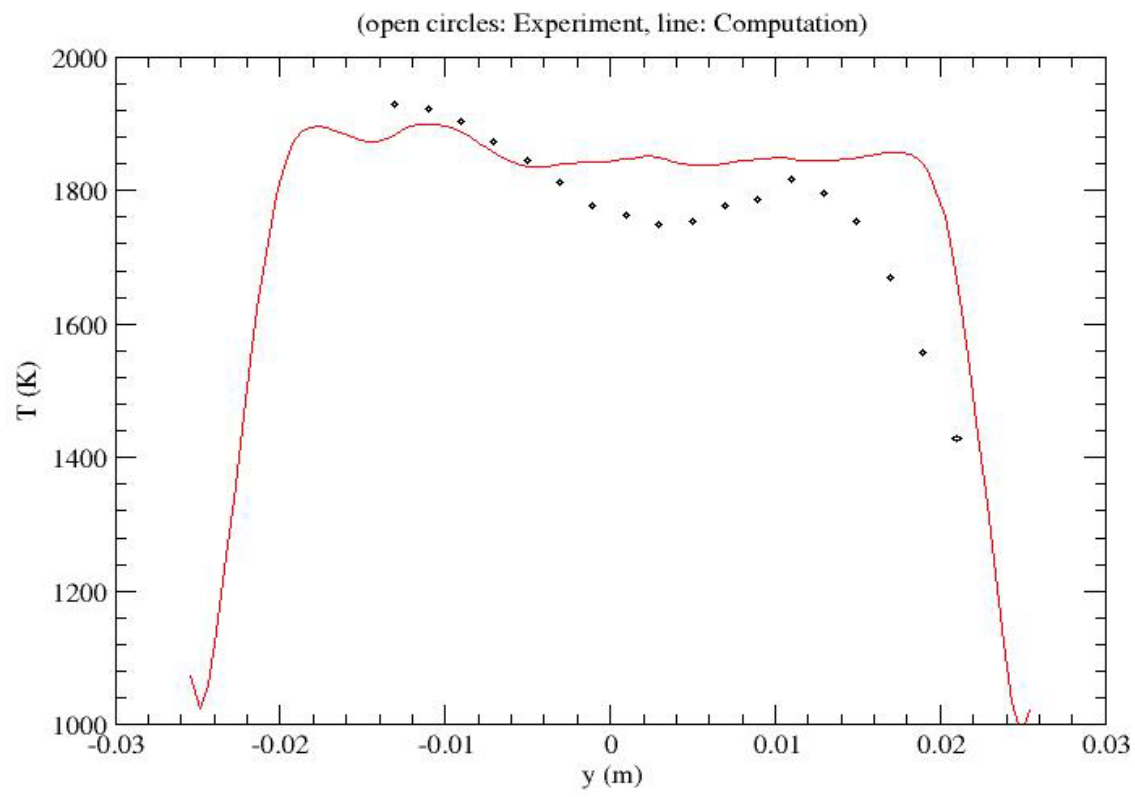

Figure 16.-Radial profile of averaged temperature $(20 \mathrm{~mm}$ downstream of the dump plane).

Radial profile of the averaged temperature at $20 \mathrm{~mm}$ downstream of the dump plane is shown in Figure 16. Radial profiles of the averaged axial velocity and the averaged azimuthal velocity at $29 \mathrm{~mm}$ downstream of the dump plane are shown in Figure 17 and Figure 18, respectively. There are still discrepancies, it is apparent that grid resolution in the near wall region needs to be improved. Radial profiles of averaged temperature, averaged axial velocity, and averaged azimuthal velocity at further downstream locations are presented in Figure 19, Figure 20, and Figure 21, respectively. Figure 19 indicates that some experimental uncertainty in the temperature measurement may exist, as suggested by its cross-stream gradient. 


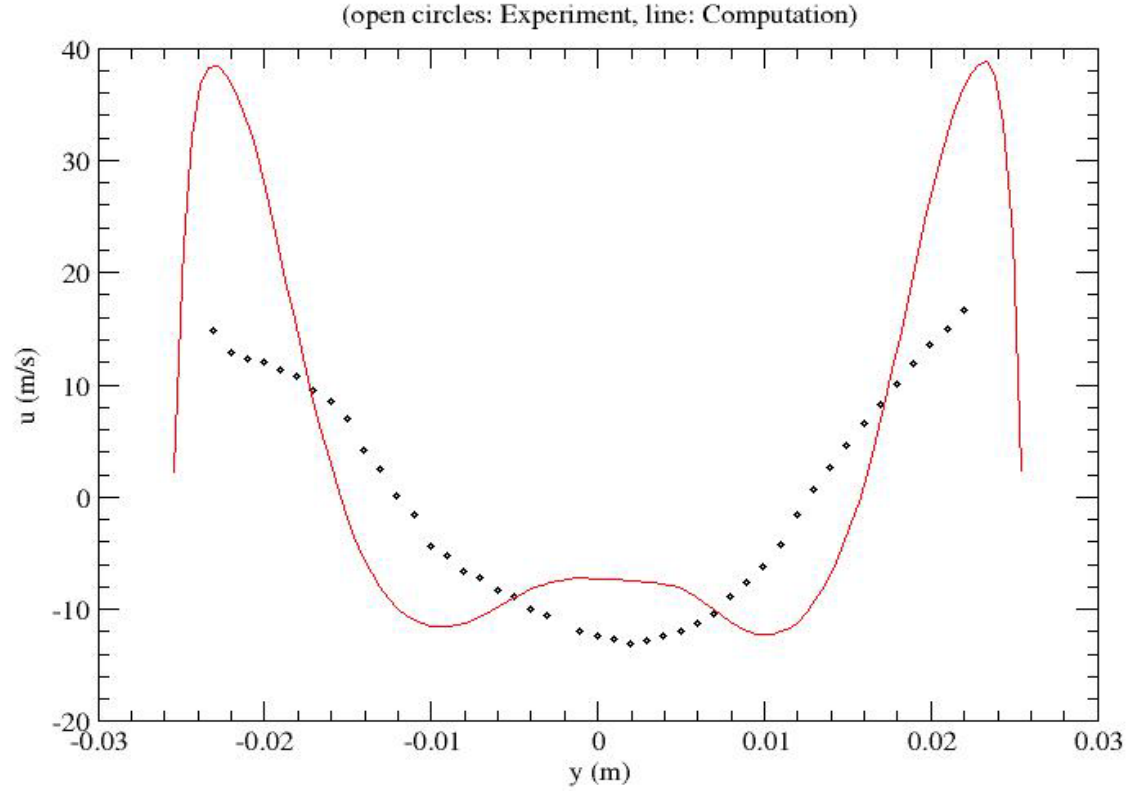

Figure 17.-Radial profile of averaged axial velocity ( $29 \mathrm{~mm}$ downstream of the dump plane).

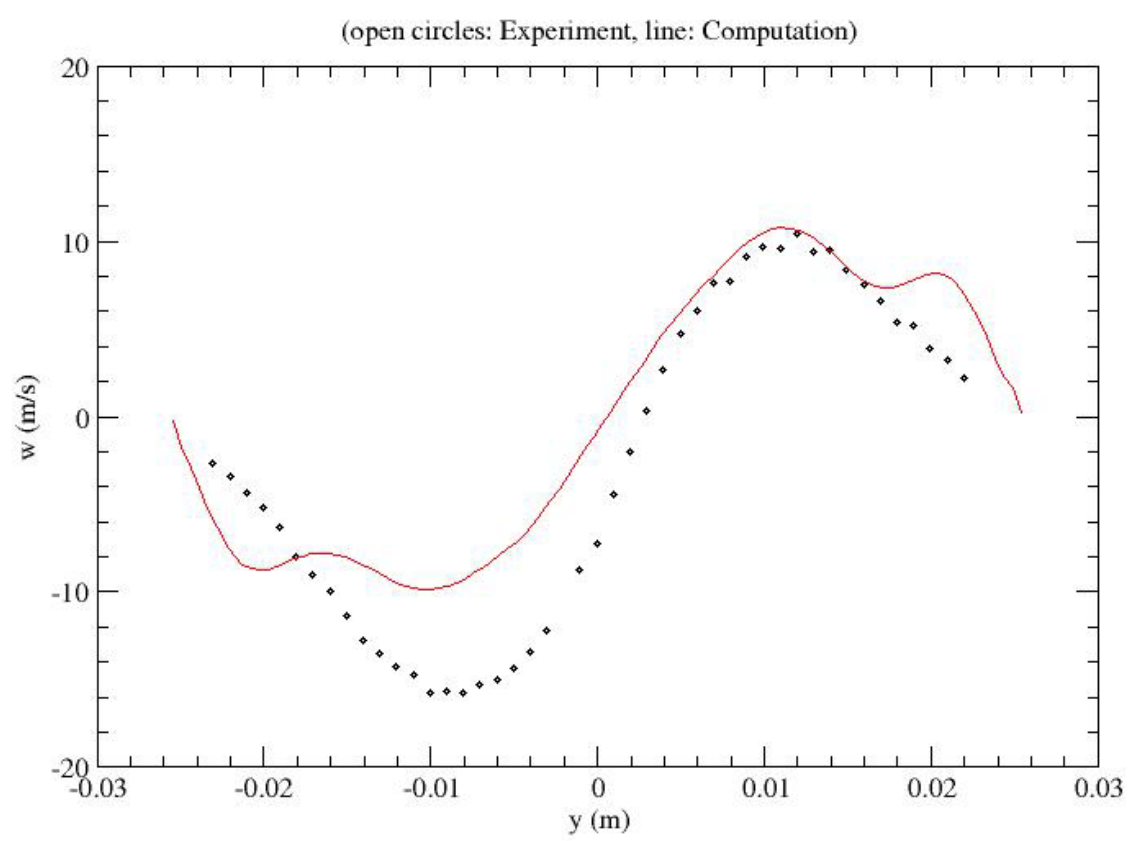

Figure 18.-Radial profile of averaged azimuthal velocity $(29 \mathrm{~mm}$ downstream of the dump plane). 


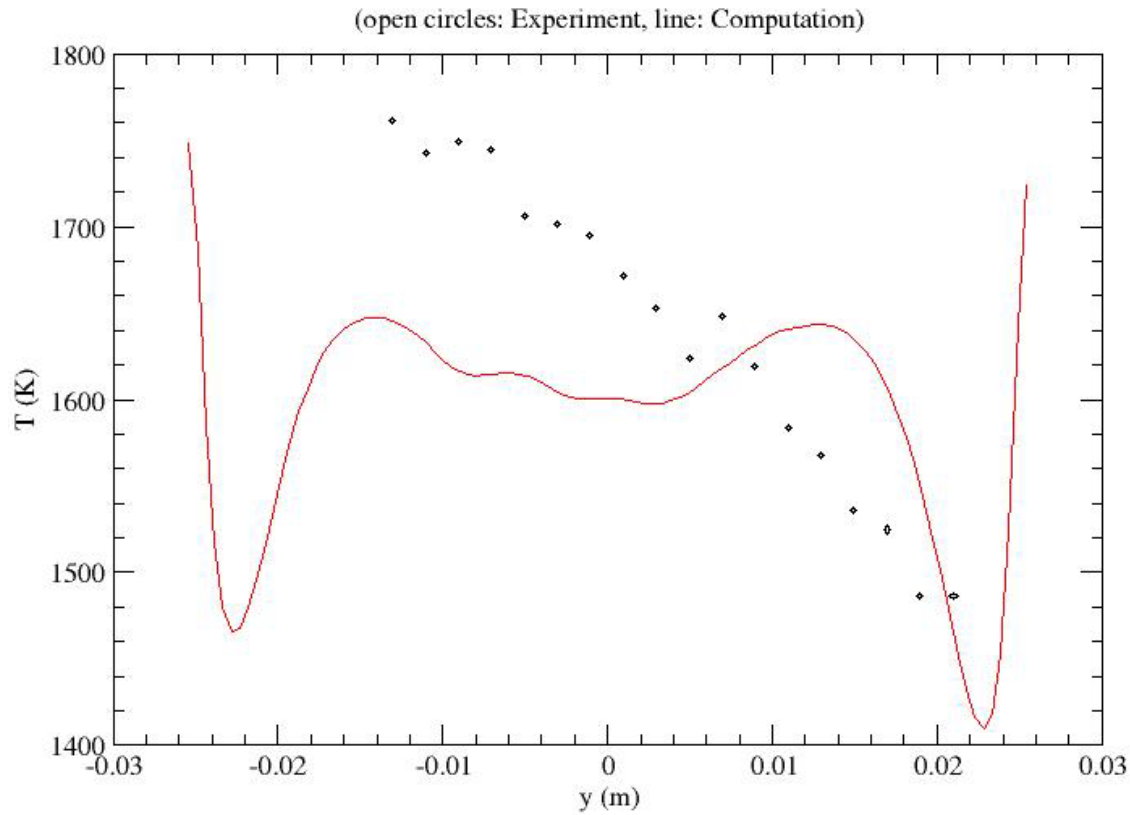

Figure 19.-Radial profile of averaged temperature $(40 \mathrm{~mm}$ downstream of the dump plane).

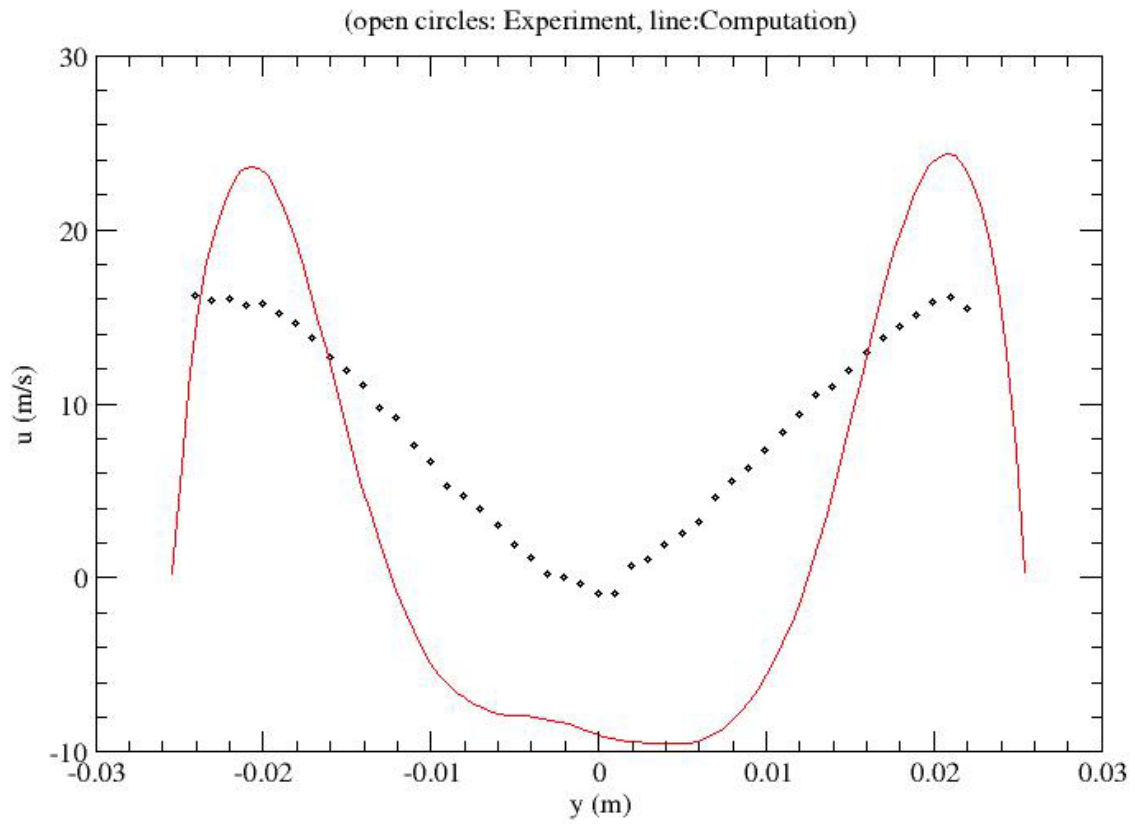

Figure 20.-Radial profile of averaged axial velocity ( $46 \mathrm{~mm}$ downstream of the dump plane). 


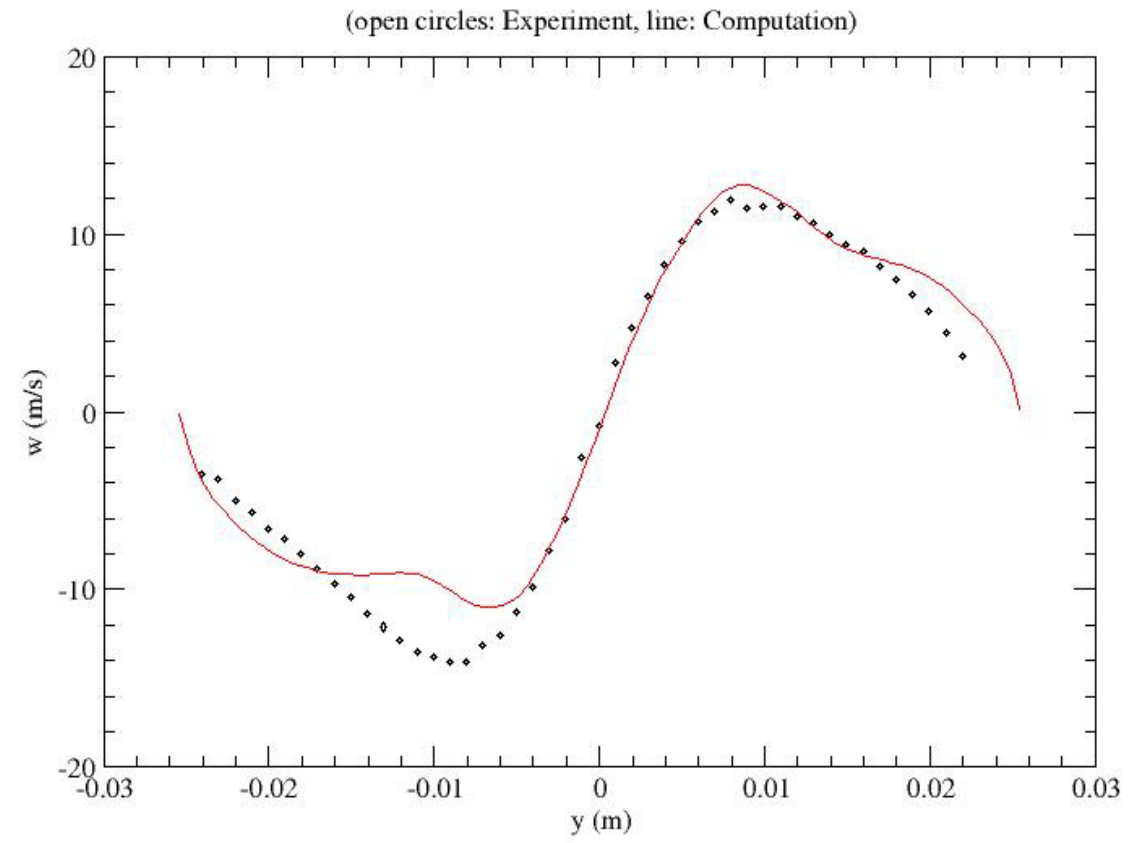

Figure 21.-Radial profile of averaged azimuthal velocity $(46 \mathrm{~mm}$ downstream of the dump plane).

\subsection{Concluding Remarks}

Two-phase turbulent combustion in a single-element LDI combustor is calculated by employing the TFNS/LEM-like approach. Together with an assumed injection condition of fuel droplets and a singlestep, five-species global reduced kinetics for the combustion, preliminary results are obtained by using a computational grid consisting of approximately 862,000 hexahedral cells. These results are useful in gaining deepened insight into the unsteady physical processes in the LDI combustor, but their quantitative accuracy suffers from the inherent uncertainties in current spray-related models. Future plan includes replacing the present combustion chemistry with, say, a three-step, seven-species global reduced mechanism, achieving a grid-independent solution, and employing atomization as well as breakup models to characterize the fuel injection processes.

\section{References}

1. Shih, T.-H., "Constitutive Relations and Realizability of Single-Point Turbulence Closures," Turbulence and Transition Modeling, Chapter 4, edited by Hallback, M., Henningson, D.S., Johansson, A.V. and Alfredsson, P.H., Kluwer Academic Publishers, 1996.

2. Shih, T.-H., "Some Developments in Computational Modeling of Turbulent Flows," Fluid Dynamic Research, Vol. 20, 1997, pp. 67-96.

3. Shih, T.-H. and Liu, N.-S., "A Nonlinear Dynamic Subscale Model for PRNS/VLES of Internal Combustor Flows," AIAA-2009-0467, 47 ${ }^{\text {th }}$ AIAA Aerospace Science Meeting and Exhibit, 4-8 January 2009, Orlando, FL.

4. Raju, M.S., "LSPRAY-III: A Lagrangian Spray Module,” NASA/CR-2008-215290, 2008.

5. Patel, N., and Suresh, M., "Simulation of Spray-Turbulence-Flame Interactions in a Lean Direct Injection Combustor," Combustion and Flame Vol. 153, 2008, pp. 228-257.

6. Cai, J., Jeng, S.-M., and Tacina, R., "The Structure of a Swirl-Stabilized Reacting Spray Issued from an Axial Swirler," AIAA-2005-1424, 43 ${ }^{\text {rd }}$ AIAA Aerospace Science Meeting and Exhibit, 10-13 January 2005, Reno, NV. 
7. Iannetti, A.C. and Liu, N.-S., "The Effect of Spray Initial Conditions on Heat Release and Emissions in LDI CFD Calculations," AIAA-2008-1150, $46^{\text {th }}$ AIAA Aerospace Science Meeting and Exhibit, 710 January 2008, Reno, NV.

8. Knudsen, E. and Pitsch, H., "Large Eddy Simulation of a Spray Combustor Using a Multi-regime Flamelet Approach,” Annual Research Briefs 2010, Center for Turbulence Research, Stanford University, pp. 337-350.

9. Liu, N.-S. and Shih, T.-H., "A Very Large Eddy Simulation of the Non-reacting Flow in a SingleElement Lean Direct Injection Combustor Using PRNS with a Nonlinear Subscale Model," ISROMAC-13-36, Proceedings of the $13^{\text {th }}$ International Symposium on Transport Phenomena and Dynamics of Rotating Machinery, 4-9 April 2010, Honolulu, HI. 



\begin{tabular}{|c|c|c|}
\hline \multicolumn{2}{|c|}{ REPORT DOCUMENTATION PAGE } & $\begin{array}{l}\text { Form Approved } \\
\text { OMB No. 0704-0188 }\end{array}$ \\
\hline \multicolumn{3}{|c|}{$\begin{array}{l}\text { The public reporting burden for this collection of information is estimated to average } 1 \text { hour per response, including the time for reviewing instructions, searching existing data sources, gathering and maintaining the } \\
\text { data needed, and completing and reviewing the collection of information. Send comments regarding this burden estimate or any other aspect of this collection of information, including suggestions for reducing this } \\
\text { burden, to Department of Defense, Washington Headquarters Services, Directorate for Information Operations and Reports (0704-018), } 1215 \text { Jefferson Davis Highway, Sulite } 1204 \text {, Arlington, VA } 22202-4302 \text {. } \\
\text { Respondents should be aware that notwithstanding any other provision of law, no person shall be subject to any penalty for failing to comply with a collection of information if it does not display a currently valid OMB } \\
\text { control number. } \\
\text { PLEASE DO NOT RETURN YOUR FORM TO THE ABOVE ADDRESS. }\end{array}$} \\
\hline $\begin{array}{l}\text { 1. REPORT DATE (DD-MM-YYYY) } \\
01-05-2013\end{array}$ & $\begin{array}{l}\text { 2. REPORT TYPE } \\
\text { Technical Memorandum }\end{array}$ & 3. DATES COVERED (From - To) \\
\hline \multirow{3}{*}{\multicolumn{2}{|c|}{$\begin{array}{l}\text { 4. TITLE AND SUBTITLE } \\
\text { Time-Filtered Navier-Stokes Approach and Emulation of Turbulen }\end{array}$}} & 5a. CONTRACT NUMBER \\
\hline & & 5b. GRANT NUMBER \\
\hline & & 5c. PROGRAM ELEMENT NUMBER \\
\hline \multirow{3}{*}{\multicolumn{2}{|c|}{$\begin{array}{l}\text { 6. AUTHOR(S) } \\
\text { Liu, Nan-Suey; Wey, Thomas; Shih, Tsan-Hsing }\end{array}$}} & 5d. PROJECT NUMBER \\
\hline & & 5e. TASK NUMBER \\
\hline & & $\begin{array}{l}\text { 5f. WORK UNIT NUMBER } \\
\text { WBS 794072.02.03.05.01 }\end{array}$ \\
\hline \multicolumn{2}{|c|}{$\begin{array}{l}\text { 7. PERFORMING ORGANIZATION NAME(S) AND ADDRESS(ES) } \\
\text { National Aeronautics and Space Administration } \\
\text { John H. Glenn Research Center at Lewis Field } \\
\text { Cleveland, Ohio 44135-3191 }\end{array}$} & $\begin{array}{l}\text { 8. PERFORMING ORGANIZATION } \\
\text { REPORT NUMBER } \\
\text { E-18670 }\end{array}$ \\
\hline \multirow{2}{*}{\multicolumn{2}{|c|}{$\begin{array}{l}\text { 9. SPONSORING/MONITORING AGENCY NAME(S) AND ADDRESS(ES) } \\
\text { National Aeronautics and Space Administration } \\
\text { Washington, DC 20546-0001 }\end{array}$}} & $\begin{array}{l}\text { 10. SPONSORING/MONITOR'S } \\
\text { ACRONYM(S) } \\
\text { NASA }\end{array}$ \\
\hline & & $\begin{array}{l}\text { 11. SPONSORING/MONITORING } \\
\text { REPORT NUMBER } \\
\text { NASA/TM-2013-217873 }\end{array}$ \\
\hline \multicolumn{3}{|c|}{$\begin{array}{l}\text { 12. DISTRIBUTIONIAVAILABILITY STATEMENT } \\
\text { Unclassified-Unlimited } \\
\text { Subject Categories: } 01 \text { and } 64 \\
\text { Available electronically at http://WWw.sti.nasa.gov } \\
\text { This publication is available from the NASA Center for AeroSpace Information, 443-757-5802 }\end{array}$} \\
\hline
\end{tabular}

\section{ABSTRACT}

This paper describes the time-filtered Navier-Stokes approach capable of capturing unsteady flow structures important for turbulent mixing and an accompanying subgrid model directly accounting for the major processes in turbulence-chemistry interaction. They have been applied to the computation of two-phase turbulent combustion occurring in a single-element lean-direct-injection combustor. Some of the preliminary results from this computational effort are presented in this paper.

\section{SUBJECT TERMS}

Combustion; CFD

\begin{tabular}{|l|l|l|l|l|l|}
\hline \multicolumn{2}{|l|}{ 16. SECURITY CLASSIFICATION OF: } & $\begin{array}{l}\text { 17. LIMITATION OF } \\
\text { ABSTRACT }\end{array}$ & $\begin{array}{l}\text { 18. NUMBER } \\
\text { OF } \\
\text { PAGES }\end{array}$ & $\begin{array}{l}\text { 19a. NAME OF RESPONSIBLE PERSON } \\
\text { STI Help Desk (email:help@sti.nasa.gov) }\end{array}$ \\
\cline { 1 - 2 } $\begin{array}{l}\text { a. REPORT } \\
\text { U }\end{array}$ & $\begin{array}{l}\text { b. ABSTRACT } \\
\text { U }\end{array}$ & $\begin{array}{l}\text { c. THIS } \\
\text { PAGE } \\
\text { U }\end{array}$ & UU & 30 & $\begin{array}{l}\text { 19b. TELEPHONE NUMBER (include area code) } \\
\text { 44-757-5802 }\end{array}$ \\
\end{tabular}



